Chapter 19

\title{
Distribution, Mechanisms, Impact and Management of Insecticide Resistance in Malaria Vectors: A Pragmatic Review
}

\author{
Vincent Corbel and Raphael N'Guessan \\ Additional information is available at the end of the chapter \\ http://dx.doi.org/10.5772/56117
}

\section{Introduction}

Malaria is still a major burden causing the death of nearly 655,000 people each year, mostly in children under the age of five, and affecting those living in the poorest countries [1]. Currently, the major obstacles to malaria control and elimination are the absence of a protective vaccine, the spread of parasite resistance to anti-malarial drugs and the mosquito resistance to insecticides [2]. Controlling mosquito vectors is fundamental to reduce mosquito-borne diseases by targeting vectorial capacity and hence the transmission. Vector control through the use of chemicals for mosquito bed nets and indoor residual spraying is still the cornerstone of malaria prevention [1]. Unfortunately, the extensive use of insecticides since the 1950s has led to the development of strong resistance worldwide hence representing a major public health problem where insecticidal vector control is implemented. Here, we propose to review the current level, distribution and mechanisms of insecticide résistance in malaria vectors and address their impact on the efficacy of vector control interventions. Strategies to prevent and/or delay the spread of insecticide resistance in natural mosquito populations are also discussed.

\section{Definition of resistance}

According to the World Health Organization (WHO), resistance is defined as the ability of an insect to withstand the effects of an insecticide by becoming resistant to its toxic effects by means of natural selection and mutations [3]. This definition differs from that provided by the Insecticide Resistance Action committee (IRAC) (www.irac-online.org) that gathers independent scientists and experts belonging to Agrochemical Companies who define operational (field) resistance as a heritable change in the sensitivity of a pest population that is reflected in the 
repeated failure of a product to achieve the expected level of control when used according to the label recommendation for that pest species. The IRAC definition, although pragmatic, is less "sensitive" with the scope to implement early Insecticide Resistance Management (IRM) strategies in the field. In both cases however, appropriate tools (biological, biochemical and/or molecular) are needed to identify the mechanisms involved and to conduct surveillance at individual and/or population levels [4].

Resistance has been observed in more than 500 insect species worldwide among which more than 50 Anopheles species (Diptera: Culicidae) are responsible for the transmission of malaria parasites to humans [5]. Resistance is a heritable character that relies on a genetic basis. Resistance results from the selection of a genetic modification in one or several genes occurring by migration and/or mutation. For example, when a mosquito population is exposed to an insecticide $\mathrm{A}$, the individuals having resistant genes to this insecticide A survive and reproduce until the resistant allele becomes almost fixed. The use of insecticides for agricultural purposes and more recently for public health has played pivotal step in the selection of resistance in malaria vectors [6]. Resistance can involve several physiological and/or behavioural changes. Changes in the insecticide target site that reduce its binding to insecticides (known as targetsite resistance) is the best understood type of resistance mechanism and molecular diagnostics to detect this resistance mechanism are now integrated into insecticide resistance monitoring strategies in malaria control programmes $[7,8]$. Enhanced insecticide metabolism that lowers the amount of insecticide reaching the target site (known as metabolic resistance) is more complex but recent advances have identified key enzymes responsible for insecticide detoxification, paving the way for the development of molecular markers for this type of resistance mechanism $[9,10]$. Other physiological changes (e.g. reduce penetration through cuticular resistance) and/or behavioural changes in the mosquito population were identified but their impact on the efficacy of insecticides is still poorly understood.

It is commonly accepted that the enhanced metabolism and target site modifications are responsible for high level of insecticide resistance in malaria vectors. To date, malaria vectors have developed resistance to the main chemical classes used in public health (i.e. pyrethroids, DDT, carbamates and organophosphates) (table 1) and the occurrence of cross-resistance ${ }^{1}$ and multiple resistance ${ }^{2}$ represent a serious threat to achieving the Millennium Development Goals for malaria control (i.e 75\% reduction of global malaria cases by 2015). Surveillance and routine monitoring campaigns to assess the level and type of resistance are essential to help Malaria Control Programme (MCPs) to design more effective and sustainable malaria vector control strategies at an operational scale [4].

\section{History of resistance to public health insecticides}

Since the humans used chemicals for crop protection and/or the prevention of vector borne diseases, cases of resistances have been reported [11, 12]. Insecticides used for malaria control

1Cross resistance: occurs when a resistance mechanism, which allows insects to resist one insecticide, also confers resistance to another insecticide. Cross resistance can occur between insecticides from different chemical classes.

2Multiple resistance: occurs when insects develop resistance to several compounds by expressing multiple resistance mechanisms. The different resistance mechanisms can combine to provide resistance to multiple classes of products. 
have included organochlorine, organophosphorus, carbamate, and pyrethroid insecticides, with the latter now taking increasing market share for both indoor residual spraying and Long Lasting Insecticidal mosquito Nets (LLINs) programmes [13]. Resistance has naturally tended to follow the use and switches of these insecticides [5].

\begin{tabular}{|c|c|c|c|c|}
\hline \multirow{2}{*}{ Insecticides } & \multirow{2}{*}{ Molecular target } & \multicolumn{2}{|c|}{ Resistance mechanis ms } & \multirow{2}{*}{ References } \\
\hline & & target site & enzymatic mechanisms & \\
\hline Pyrethroids, type I & sodium channel & Kdr and super Kdr mutations & monooxygenases + esterases & {$[10,61,62]$} \\
\hline Pyrethroids, Type II & sodium channel & Kdr mutations & monooxygenases + esterases & {$[10,61,62]$} \\
\hline Organochlorates & sodium channel & Kdr mutations & $\begin{array}{l}\text { GS-tranferases + } \\
\text { monooxygenases }\end{array}$ & {$[10,61,62]$} \\
\hline $\mathrm{N}$-alkyl-amides & sodium channel & \multicolumn{2}{|c|}{ no resistance reported a gainst insect of public health importance } & \\
\hline Organophosphates & acetylcholinesterase & Ace $1^{R}$ mutation & $\begin{array}{l}\text { esterases + GS-tranferases + } \\
\text { monooxygenases }\end{array}$ & {$[10,59,63-67]$} \\
\hline Carbamates & acetylcholinesterase & Ace $1^{R}$ mutation & & {$[10,59,63-67\rceil$} \\
\hline Neonicotinoids & nicotinic acetycholine receptor & not reported & monooxygenases & {$[68,69]$} \\
\hline Spinosad & nicotinic acetycholine receptor & not reported & & \\
\hline $\begin{array}{l}\text { Cyclodienes, Lindane, } \\
\text { Bicyclic phosphates }\end{array}$ & GABA receptor & Rdl mutation & GS-transferases & {$[62,70]$} \\
\hline Phenylpyrazoles & GABA receptor & Rdl mutation & GS-transferases & {$[62,70]$} \\
\hline Avermectines & GABA receptor & undiscribed & monooxygenases + esterases & {$[62,70]$} \\
\hline Insect Growth Regulators & $\begin{array}{l}\text { Ecdysone agonist/disruptor or } \\
\text { inhibitor of ATP synthase, chitin } \\
\text { biosynthesis or lipid synthesis }\end{array}$ & no resistance reported against & sect of public health importance & \\
\hline $\begin{array}{l}\text { Bacillus thuringiensis var. } \\
\text { israelensis }\end{array}$ & $\begin{array}{l}\text { microbial disruptors of insect midgut } \\
\text { membranes }\end{array}$ & reported against $\mathrm{C}$ ulex $\mathrm{pi}$ & ens s.l. but non discribed & [71] \\
\hline
\end{tabular}

Table 1. Mechanisms of insect resistance to the main insecticide families of public health interest

Historically, DDT was first introduced for mosquito control and malaria eradication programme in 1946. The first case of DDT resistance was reported in An. sacharovi in Greece in 1953 and was followed by dieldrin resistance in 1954 [15]. Onset of resistance was marked by deterioration in malaria control that has continued for more than 30 years with sporadic epidemics of disease [16]. Resistance in An. sacharovi has been later reported in Bulgaria, Lebanon, Iran, Iraq, and Syria [12]. Pronounced DDT resistance appeared in An. stephensi in Iran and Iraq when full scale house spraying operations began in 1957 and dieldrin resistance appeared three years later. In India, house-spraying of DDT and Lindane $(\mathrm{HCH})$ under the public health programme was introduced in the 1950s. Resistance of the main malaria vector An. culicifacies to dieldrin developed in 1958 [17] and resistance to DDT in 1959 [18], but the malaria control programme continued until 1965-1966 when both DDT and HCH failed to control outbreaks of malaria [19]. As a result, malathion was introduced in some areas in 1969 with some success but An. culicifacies rapidly developed resistance by 1973 [20]. Malathion resistance resulted in colossal epidemics of malaria in 1975 with 4 million cases reported as compared with 125,000 in 1965. The experience in Pakistan was similar with DDT resistance appearing in 1963. The importance of the resistance was not recognized until outbreaks of malaria began in 1969 and neither DDT nor HCH was effective. By 1975, malaria cases were reported in Pakistan to number 100 million as compared to 9,500 in 1961 [12]. DDT resistance in An. culicifacies was reported in Sri Lanka in 1968 resulting in a severe epidemic of malaria 
[21]. This vector is now resistant to DDT, dieldrin, organophosphates, carbamates and pyrethroids [11].

Similar trend was noted in Central America and the Caribbean. Dieldrin spraying against An. albimanus begun in 1956 and widespread resistance appeared in 1958 [12]. A return to DDT spraying produced generalized resistance by 1960 [18]. The carbamate propoxur was employed in El Salvador, Guatemala, Honduras and Nicaragua in 1970 and resistance developed by 1974. An albimanus now exhibits multiple resistances to DDT, dieldrin, lindane and other chemical recently used in public health [22].

Much less information is however available for South East Asian malaria vectors, most probably because resistance monitoring was not carried out in routine before the $80 \mathrm{~s}$. In Vietnam, DDT resistance was found in 1989 in An. epiroticus of the Sundaicus Complex and is still occurring [23]. From 1990 till 2000, pyrethroid resistance was almost absent in all tested species except in some populations of An. vagus and An. minimus s.l. [24]. In Thailand, no evidence of insecticide resistance in malaria vectors was present before 1985 [25]. In 1986, development of physiological resistance to DDT was detected in An. aconitus from the north where DDT was commonly used for malaria control. One year later, DDT resistance was found in field collected mosquitoes of An. philippinenis, An. nivipes and An. aconitus from the same northern region. Between 1990 and 1997, DDT resistance has been detected in the three primary malaria vectors An. dirus s.l., An. minimus s.l. and An. maculatus s.l. and permethrin resistance was suggested in a population of An. minimus s.l. from northern Thailand, based however on a lower discriminative dosage $(0.25 \%)$ of permethrin than that used today [25].

In Africa, resistance was initially found in An. gambiae in Bobo Dioulasso by 1967 (Burkina Faso), hence less than 7 years after the end of DDT use for malaria control [12]. DDT resistance was found in neighbouring countries including Cote d'Ivoire, Nigeria and Mali [26] and was then reported in most of Central and East African countries [27]. Strong association was observed between the level of DDT resistance in malaria vectors and the amount of DDT use for cotton protection [28]. Regarding BHC/dieldrin, the first cases of resistance were reported in Nigeria in 1954 hence only few months after the introduction of this molecule for malaria control. Initially found in very limited geographical areas, dieldrin resistance has spread in areas free of any insecticide treatments [29]. Few years later, resistance was reported in BoboDioulasso and Cote d'Ivoire [30]. Today, resistance to BHC/dieldrin is still widespread in wild field anopheline populations despite its abandon in public health for many decades [31]. As for DDT, dieldrin resistance in malaria vectors arose and persisted from intensive use of pesticide for agricultural practices and in some specific settings due to public health programmes $[32,33]$.

After the 80s, DDT has been more or less abandoned worldwide and replaced by organophosphate $(\mathrm{OP})$, pyrethroids and, to lesser extent, carbamates. However, insecticide resistance continued to be a problem, and vector control operations were affected, particularly in India, Africa and Latin America, by extensive use of agricultural pesticides. OP resistance, either in the form of broad-spectrum OP resistance or malathion-specific resistance was found in the major malaria vector species worldwide [12]. Pyrethroids were introduced in late 70s in public health and increasingly used in the 90s; however, cases of resistance were rapidly reported in 
the main malaria vectors worldwide including An. albimanus [34], An. darlingi [35], An. culicifacies [36], An. stephensi [37], An. gambiae [38], An. funestus [39] and An minimus [40]. Despite a sporadic use (compared to DDT and pyrethroids), resistance to carbamates was earlier reported in several mosquito species including An. albimanus [41], An. atroparvus [42], An. sacharovi [5] and An. gambiae [43]. Carbamate resistance is now spreading in malaria vectors especially in West Africa where it has been reported in Cote d'Ivoire [44], Burkina Faso [45, 46], Benin [47] and Nigeria [48]. Increased level of carbamate resistance in African mosquito populations is worrying for malaria control because these chemicals are increasingly used in replacement to pyrethroids for Indoor Residual Spraying (IRS) [49].

It is obvious that insecticide resistance in malaria vectors is increasing worldwide due to the increasing selection pressure on mosquito populations caused by the presence of urban, domestic and/or agricultural pollutants in the environment [50]. Transversal and longitudinal monitoring surveys are essential to address the spatio-temporal changes in resistance (dynamic) and to design appropriate strategies for a better control of resistant malaria vector populations worldwide.

\section{Resistance mechanisms}

The various mechanisms that enable insects to resist the action of insecticides can be grouped into four distinct categories including metabolic resistance, target-site resistance, reduce penetration and behavioral avoidance. These mechanisms that are shown in the figure 1 are briefly described in the following sections.

\subsection{Metabolic resistance}

Metabolic resistance is the most common resistance mechanism that occurs in insects. This mechanism is based on the enzyme systems which all insects possess to help them to detoxify naturally occurring xenobiotics/insecticides. It is commonly accepted that insect detoxification systems derived from the plant-insect evolutionary arm race and several insect detoxification enzymes have been associated to the detoxification of plant toxins and all types of chemicals, including insecticides [51]. Over-expression of enzymes capable of detoxifying insecticides or amino acid substitutions within these enzymes, which alter the affinity of the enzyme for the insecticide, can result in high levels of insecticide resistance (see [52] for review). Increased expression of the genes encoding the major xenobiotic metabolizing enzymes is the most common cause of insecticide resistance in mosquitoes. Over expression of detoxyfing enzymes can occur as the result of gene amplification (e.g. duplication) or due to changes in either transacting regulator elements or in the promoter region of the gene $[5,53,54]$. The consequence is a significant increase of enzyme production in resistant insects that enables them to metabolize or degrade insecticides before they are able to exert a toxic effect. Three categories of enzymes, namely esterases, P450s and glutathione-S-transferases are known to confer resistance to insecticides in insect pest such as malaria vectors. These large enzyme families contain multiple enzymes with broad overlapping substrate specificities, and one member of the family might 


\section{(a) susceptible insect}

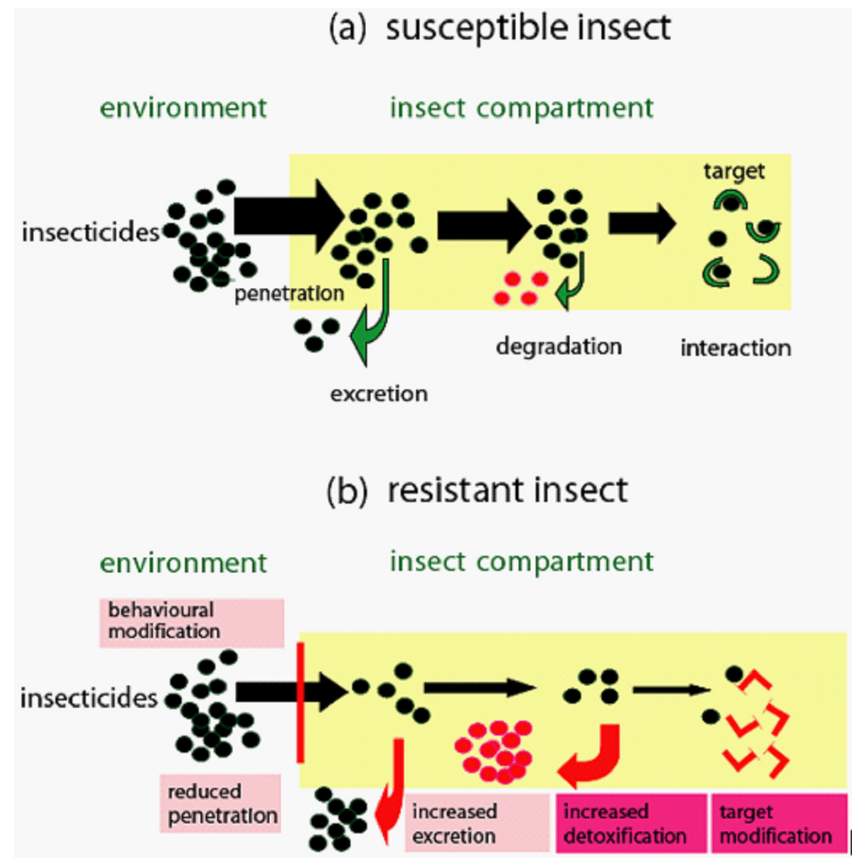

Figure 1. Scheme of potential behavioral and physiological changes associated with insecticide resistance in malaria vectors; (a) susceptible insect; (b) resistant insect (source ; see [14])

be capable of metabolizing limited number of insecticides. Similarly, the level of resistance conferred can vary from low to very high and may differ from compound to compound. Metabolic resistance mechanisms have been identified in mosquito populations for all major classes of insecticides currently used for vector control, including organochlorine, organophosphates, carbamates, and pyrethroids.

Esterases. One of the most common metabolic resistance mechanisms is that of elevated levels, or activity, of esterase enzymes which hydrolyze ester bonds or sequester insecticides. A striking example comes from studies on Culex quinquefasciatus that resist to a broad range of OP insecticides. In this species, multiple copies of EST-genes was already found hence enabling it to overproduce this type of enzyme [55]. In contrast to the situation in Culex, a number of Anopheles species (ie An. culicifacies, An. stephensi and An. arabiensis) have a non-elevated esterase mechanism that confers resistance specifically to malathion through increased rates of metabolism. Malathion resistance in Anopheles spp was associated with an altered form of esterase that specifically metabolizes the molecule at a much faster rate than that in susceptible counterparts [56, 57]. Although Carboxylesterase (CCEs) have been mostly associated to organophosphate resistance in mosquitoes, their role in pyrethroid resistance is probable. Indeed, the ability of esterases to metabolize pyrethroids has been suggested in mosquitoes $[58,59]$ even if no specific mosquito CCE has yet been validated as a pyrethroid metabolizer 
[50]. Clearly much more information is needed on the esterase-mediated resistance in malaria vectors.

P450s. Cytochrome P450-dependent monooxygenases are an important and diverse family of enzymes involved in the metabolism of numerous endogenous and exogenous compounds. P450 belong to six families and increased transcription of genes belonging to the CYP4, CYP6, and CYP9 has been observed in various insecticide-resistant species from different taxa [60]. There is increasing number of reports demonstrating elevated P450 monooxygenase activities in insecticide-resistant mosquitoes, frequently in conjunction with altered activities of other enzymes. In most cases where a link between insecticide resistance and elevated P450 activity has been shown, the CYP gene belongs to the CYP6 family. Since the publication of the An. gambiae genome [61], P450s were extensively studied in the primary malaria vector in Africa. A total of 111 P450 enzymes were identified [62] and, as in other insects, only a small number of these enzymes are capable of detoxifying insecticides. However, higher activity of enzymes and/or expression of detoxification genes in insecticide resistant colonies do not necessarily correlate with insecticide resistance. For example, some authors have shown elevated transcript levels of an adult-specific CYP6 P450 gene, CYP6Z1, in pyrethroid-resistant strain of An. gambiae [63, 64] and An. funestus [65]. Further validation studies conducted in An. gambiae showed that cyp6z1 was however not capable to metabolize pyrethroids but was capable to metabolize DDT [66]. Another study showed that CYP6z2 displays broad substrate specificity, which may be associated with xenobiotics metabolism and detoxification [67]. Despite, CYP6Z2 being able to bind to permethrin and cypermethrin, this gene does not metabolise any of these insecticides. Microarray-based approaches have lately identified three new "candidate" P450 genes that were found to be repeatedly over-produced in pyrethroid resistant populations of An. gambiae: CYP6M2, CYP6P3 and CYP6Z2 [68-70]. All of these genes encode for enzymes that are able to bind to type I and type II pyrethroids but only CYP6P3 and CYP6M2 showed to metabolize the insecticides [10, 71]. More recently, some authors demonstrated that CYP6M2 is also capable of metabolizing the organochlorine insecticide DDT in An. gambiae, hence demonstrating the first evidence for a metabolic cross-resistance in malaria vectors [9]. Interestingly the putative ortholog of An. gambiae CYP6P3, CYP6P9, as being the prime candidate for conferring pyrethroid resistance, have been identified in An. funestus [72, 73] but only the CYP6P9 showed to metabolize types I and II pyrethroids [74]. Recent works showed that overproduction of CYP6P9 in An. funestus result from gene duplication [72]. In An. minimus mosquito, CYP6AA3 and CYP6P7 were up-regulated in pyrethroid-resistance population of Thailand [75] and seem to possess activities toward pyrethroid degradation [76, 77].

Glutathione S-transferases (GSTs). Glutathione transferases (GSTs) are multifunctional enzymes involved in the detoxification of many endogenous and xenobiotic compounds. Conjugation of Glutathione (GSH) to such organic molecules enhances solubility, thus facilitating their eventual elimination [78]. Elevated GST activity has been implicated in resistance to at least four classes of insecticides in insects. Higher enzyme activity is usually due to an increase in the amount of one or more GST enzymes, either as a result of gene amplification or more commonly through increases in transcriptional rate, rather than 
qualitative changes in individual enzymes [52]. At least six classes of insect GSTs have been identified in An. gambiae [79], found in several large clusters on all three chromosomes. The Delta and Epsilon classes found exclusively in insects are the largest classes of insect GSTs. Members of both classes have been implicated in resistance to all the major classes of insecticide. The primary role of GSTs in mosquito insecticide resistance is in the metabolism of DDT to DDE (non toxic products), although they also have a secondary role in organophosphate resistance [80]. GST-based DDT resistance is common in a number of anopheline species including An. gambiae [81-83], reflecting the heavy use of this insecticide for malaria control over several decades. Molecular biology and in vitro expression studies showed that aggst3-2 was over expressed in resistant strain of An. gambiae and that recombinant aggst3-2 was very efficient at metabolizing DDT [84]. Most studies of GSTs suggested that regulation occurs at the transcriptional level. Several regulatory elements have been identified in the promoter regions of GSTs that may mediate their induction but the significance of these findings is unclear. Genetic mapping of the major genes controlling GST-based DDT resistance in An. gambiae provided however evidence for a trans-acting regulator [84], although in this species, mutations in promoter elements of the Epsilon GST cluster are also associated with resistance [81]. It has been suggested that GSTs may play a role in pyrethroid resistance by detoxifying lipid peroxidation products induced by pyrethroids and/or by protecting from insecticide exposure induced oxidative stress [85]. Furthermore, GST might confer secondary role in pyrethroid resistance by sequestering the insecticide hence reducing the total in vivo concentration of insecticide [86].

Despite the great advance obtained recently in the identification of the role of detoxifying enzymes in insecticide resistance, force is to note that the function of $>90 \%$ of metabolic genes is still unknown. Although only a limited number of resistance mechanisms have been implicated to date, the diversity within enzyme families involved in metabolic resistance is likely to contribute substantially to resistance to many insecticide classes. Further functional genomics and post-genomic technology are needed to reveal the contributions of hitherto unsuspected enzymes in insecticide metabolism and/or sequestration and to identify the causal mutations associated with metabolic resistance in mosquitoes. The contribution that these enzymes make towards various insecticide resistance phenotypes in malaria vectors is yet to be elucidated.

\subsection{Target-site resistance}

The second most common resistance mechanism encountered in insects is target-site resistance. Insecticides generally act at a specific site within the insect, typically within the nervous system (e.g. OP, carbamate, DDT and pyrethroid insecticides). The site of action can be modified in resistant strains of insects such that the insecticide no longer binds effectively. Reduce sensitivity of the target receptors to insecticide results from non-silent point mutations in the gene encoding the protein. For example, the target site for OP and carbamate insecticides is acetylcholinesterase (AChE) in the nerve cell synapses. Several mutations in the gene encoding for an acetylcholinesterase have been found in insects" [87] which result in reduced sensitivity to inhibition of the enzyme by these insecticides [88, 89]. In malaria vectors, the 
G119S mutation (i.e. glycine to serine substitution at position 119) responsible for carbamate and OP resistance has been reported in An. gambiae and An. albimanus, essentially at the heterozygous state [90]. Recent sequence analysis of some resistant mosquitoes collected in Benin revealed the presence of a duplication of the ace-1 gene in both $\mathrm{A}^{*} \mathrm{n}^{*}$. A. gambiae $\mathrm{M}$ and $S$ forms [91]. In addition, mutations at a single codon (position 302) in the Rdl (resistance to dieldrin) gene encoding one receptor subunit, from an alanine residue to a serine (or more rarely to a glycine), have been documented in dieldrin-resistant insect species [92] including the malaria vectors An. stephensi [93], An. gambiae s.l. [94] and An. funestus [31]. Similarly, mutations in the amino acid sequence in the voltage-gated sodium channels of nerve cell membranes leads to a reduction in the sensitivity of the channels to the binding of DDT and pyrethroid insecticides [95]. Alterations in the target site that cause resistance to insecticides are often referred to as knockdown resistance $(k d r)$ in reference to the ability of insects with these alleles to withstand prolonged exposure to insecticides without being 'knocked-down" [96]. One of the most common amino acid replacements associated with pyrethroid resistance in malaria vectors is a substitution of the leucine residue found at codon 1014 with either phenylalanine (1014F) [97] or serine (1014S) [98] in the Voltage-Gated Sodium Channel (VGSC). Interestingly, residue 1014 does not appear to interact directly with the insecticide but is predicted to alter channel activation kinetics [99]. Note that a de novo mutation (N1575Y) recently emerged within domains III-IV of voltage gate sodium channel in pyrethroid resistant populations of An. gambiae and seems to occurs only in a single long-range haplotype, also bearing 1014F allele [100]. It has been suggested that the N1575Y mutation may compensates for deleterious fitness effects of $1014 \mathrm{~F}$ and/or confers additional resistance to pyrethroid insecticides.

\subsection{Reduced penetration}

Modifications in the insect cuticle or digestive tract linings that prevent or slow the absorption or penetration of insecticides can be found is some resistant insects. This resistance mechanism is not specific and can affect a broad range of insecticides. Reduced uptake of insecticide, often referred to as cuticular resistance, is frequently described as a minor resistance mechanism. Certainly for pests where the major route of insecticide delivery is via ingestion, this is likely to be the case. However, for malaria control, where insecticides are typically delivered on bed nets or on wall surfaces, uptake of insecticides is primarily through the appendages. An increase in the thickness of the tarsal cuticle, or a reduction in its permeability to lipophilic insecticides, could have a major impact on the bioavailability of an insecticide in vivo. Examples of reduced-penetration mechanisms are however limited; cuticular resistance was reported for the domestic Fly Musca domestica [101] and the lymphatic filariasis vector Culex quinquefasciatus [102]. In Anopheles, microarrays studies have recently identified two genes, cplcg3 and cplcg4, encoding cuticular proteins that were upregulated in pyrethroid resistant strains from four populations and two different species (i.e. An. gambiae and An. stephensi) $([69,103,104]$. Recently, measures of mean cuticle thickness in a laboratory strain of An. funestus using scanning electron microscopy (SEM) showed that the mean cuticle thickness was significantly greater in pyrethroid tolerant mosquitoes than their susceptible counterparts [105]. Clearly 
much more work is required in order to identify the significance of cuticular resistance in phenotypic resistance.

\subsection{Behavioural resistance}

Insecticide resistance in mosquitoes is not always based on biochemical mechanisms such as metabolic detoxification or target site mutations, but may also be conferred by behavioural changes in response to prolonged exposure to an insecticide. Behavioural resistance does not have the same "importance" as physiological resistance but may be considered to be a contributing factor, leading to the avoidance of lethal doses of an insecticide [106, 107]. For example, the first study on the irritant effect of DDT residual deposits was conducted using Anopheles quadrimaculatus where females were found to be irritated shortly after making contact with the treated surfaces resulting in a rapid escape response from a treated house prior to taking a blood meal [108]. This type of response can be further divided into direct contact excitation (sometimes referred to as 'irritancy') and non-contact spatial repellency that is used when insects move away from the insecticide-treated area before making direct contact $[106,109]$. Examples of behavioral resistance or avoidance are few. Change in vector composition (i.e. switch from An. minimus to An. harrisoni) has been observed following implementation of ITNs in a village form central Vietnam [110]. With regard to An. funestus, recent findings showed a shift from indoor to outdoor biting preferences in Tanzania in relation to increasing coverage of pyrethroid-impregnated net [111]. Significant changes in the hostseeking behavior of the An. funestus population was confirmed in Benin (West Africa) where scaling up of LLINs at community level induced a change from night biting to early-morning biting behaviour [112]. It is unclear however whether adaptation of malaria vectors species to insecticidal based vector control interventions such as LLIN may result from a phenotypic plasticity or from selected behavioral traits (see Durnez \& Coosemans for details).

\section{Method to detect insecticide resistance}

Currently most resistance monitoring is dependent on bioassays, using fixed insecticide concentrations and exposure times, and the data is reported as percentage mortality and/or Knock Down (KD) effect. The World Health Organisation (WHO) has defined diagnostic doses (i.e. twice the dosage that killed $100 \%$ susceptible mosquitoes of a given species) for most insecticides used in malaria control and produces susceptibility test kits consisting of exposure chambers and insecticide treated filter papers [113-115]. Although simple to perform, these diagnostic dose assays provide limited information and several alternative methods for detecting resistance are available (Table 2). These alternative assays generally detect specific resistance mechanisms, and should always be performed as an addition, not a substitute, to bioassays, to avoid the risk that unknown resistance mechanisms go undetected. It should be noted that none of the current methods listed in Table 2 are suitable for detecting cuticular and/or behavioural resistance. Regular monitoring for insecticide resistance is essential in order to react proactively to prevent insecticide resistance from compromising control. If the frequency of resistance alleles is going to build up unchecked, resistance may eventually 
become 'fixed' in the populations. Once resistance reaches very high levels, strategies to restore susceptibility are unlikely to be effective.

\begin{tabular}{lll}
\hline Method & Advantages & Disadvantages \\
\hline $\begin{array}{l}\text { Bioassays using WHO defined } \\
\text { diagnostic doses of insecticide }\end{array}$ & $\begin{array}{l}\text { Standardized, simple to perform, } \\
\text { detect resistance regardless of } \\
\text { mechanism }\end{array}$ & $\begin{array}{l}\text { Lack sensitivity and provide no } \\
\text { information about level and type of } \\
\end{array}$ \\
& & $\begin{array}{l}\text { resistance (except when using with } \\
\text { synergists), to be done on live }\end{array}$ \\
\hline Dose response bioassays & Provides data on level of resistance & mosquitoes \\
& in population, regardless of & mosquitoes, and data from different \\
\hline Biochemical assays to detect activity & Provides information on specific & groups not readily comparable \\
\hline $\begin{array}{l}\text { of enzymes associated with } \\
\text { insecticide resistance }\end{array}$ & mechanisms responsible for & Requires cold chain. Not available \\
& resistance & for all resistance mechanisms, \\
\hline Molecular assays to detect resistant & Very sensitive. Can detect recessive & Requires specialized and costly \\
alleles & alleles and therefore provide an & equipment. Only available for a \\
& 'early warning' of future resistance. & limited number of resistance
\end{tabular}

Table 2. Methods for detecting insecticide resistance (source: see [6])

\subsection{Bioassays}

Guidelines for test procedures and interpretation of results are available from the WHOPES 3 (see http://www.who.int/whopes/resistance/en/). It is important that the mosquitoes used for the bioassays are standardized for age, sex and physiological status as all of these can affect the outcome of the tests. Typically either adults raised from isofemale lines or F1 progeny from field collected blood fed females are used. The limitations and advantages of these two alternatives have recently been discussed [116].

These diagnostic dose assays are simple to perform and provide standardized data sets that, assuming the guidelines are followed, can be readily compared to identify temporal and/or geographical variations in the resistant status of malaria vector populations. However, it is important to recognize some of the limitations of these susceptibility tests. As only a single concentration of insecticide is used, the results do not provide any information about the level of resistance in a population. For example if $50 \%$ of population A and $20 \%$ of population B were killed after exposure to the diagnostic dose of permethrin, it cannot be concluded that population B is more resistant than population A. The results only indicate that both populations are resistant (according to WHO definitions if there is $<80 \%$ mortality, the population is defined as resistant) and that, subject to tests of significance, there is a higher frequency of 
resistant individuals in population B than in A. Dose response assays would be needed to compare the levels of resistance in two populations (e.g. by measuring the Resistant Ratios and their $95 \%$ confidence intervals). For pyrethroids, median knock down time (MKDT) is also a useful quantifiable variable [117]. Similarly, the results of these tests cannot be used to compare the levels of resistance to two different insecticides. If $50 \%$ mortality was observed after exposure to the diagnostic dose of permethrin $(0.75 \%)$ whereas mortality was $70 \%$ after exposure to the diagnostic dose of deltamethrin $(0.05 \%)$, it is not correct to state that the population is more resistant to permethrin than deltamethrin. Again, all that can be stated is that the population is resistant to both insecticides.

Partly due to the limitations of the diagnostic dose assays described above and partly due to the difficulties that are sometimes incurred in obtaining a regular supply of the insecticide impregnated papers from $\mathrm{WHO}$, an alternative bioassay methodology has been developed [118] and is being adopted by some monitoring programmes. This method, known as the CDC bottle bioassay, uses glass bottles coated with a known concentration of insecticide. As these test kits are assembled in the users own laboratory, the concentration of insecticide can be readily adjusted enabling dose response curves to be developed to compare two or more strains. A caveat to this is that the flexibility, and the potential variation in the insecticide grade used in the tests, impairs comparison of results between two separate studies.

Both WHO diagnostic doses and CDC bottle bioassays can be modified to incorporate synergists. Synergists such as piperonyl butoxide, that block the activity of two major detoxification enzyme families, can be used to explore the role of different resistance mechanisms. If resistance is due to increased metabolism, exposure to an appropriate synergist prior to insecticide bioassays should increase the level of mortality observed.

\subsection{Biochemical tests}

Biochemical tests to detect alterations in activities of enzyme families associated with insecticide resistance have been available for over two decades and are sometimes used in combination with insecticide bioassays [119]. These assays employ model substrates to record the overall activity of glutathione transferases, carboxylesterases or cytochrome P450s in individual insects. Biochemical assays are also available to detect target site resistance to organophosphate and carbamate insecticides caused by insensitive acetylcholinesterase (AChE). The enzymatic reaction produces a colour change that is generally visible to the naked eye and hence these assays do not require access to expensive equipment (spectrophotometer is appropriate). However, it is important that the mosquitoes are kept on ice from the point of collection to the performance of the assay and this can often pose logistical challenges. Furthermore, there are sensitivity and specificity issues that limit the utility of some of these assays. For example, with over 100 different cytochrome P450 enzymes in malaria vectors, an assay that measures the total level or activity of this enzyme family may not have the sensitivity to detect over production of the single or small number of P450 enzymes that are thought to be involved in pyrethroid metabolism. This may explain the lack of significant correlation observed in many studies between cytochrome P450 activity and bioassay mortality results $[120,121]$. In addition not all members of the enzyme family will have the same affinity for the model substrates used in these assays (e.g. CDNB (1-chloro 2-4, dinitrobenzene) is the substrate 
typically used to assess glutathione transferase activity but the Epsilon class of GSTs which are responsible for DDT resistance have relatively low activity with this substrate). In order to incorporate data from resistance monitoring into evidence based decisions on appropriate insecticide based interventions for malaria control, it is clearly essential that the data is both reliable and accessible. Although guidelines for conducting the various assays exist, there is little consensus on the number of sites and frequency with which resistance monitoring should occur [122]. It is clear that resistance is a dynamic trait, and wide fluctuations in resistance levels throughout the malaria transmission season have been reported [116, 123, 124]. Resistance can also be very focal, particularly when vector composition differs between sites [125], hence a minimum number of sampling sites should be established, taking into account patterns of vector distribution and insecticide usage. The WHO/AFRO African Network for Vector Resistance was established in 2000 and amongst its objectives was the important goal of improving the dissemination of resistance data. Accordingly a database was established to store the results of resistance monitoring activities by the African Network for Vector Resistance (ANVR) members but until recently, this database was not readily accessible by outside users. The recent establishment of new data base (see section 6), as an online centralized resource for collating data on insecticide resistance in disease vectors and the integration of this with the ANVR database, will hopefully ensure that both published and unpublished data on resistance in malaria vectors are more readily available to all interested parties.

\subsection{Molecular tests}

A multitude of molecular assays have been developed to detect $k d r$ alleles in malaria mosquitoes, several of which were recently compared in a study by Bass et al (see [126]). These are routinely used by research laboratories monitoring for insecticide resistance and are gradually being incorporated into some national malaria control resistance monitoring programmes. Unfortunately, despite the recent identification of the key enzymes responsible for metabolic resistance to pyrethroids in An gambiae and An funestus, there are currently no simple DNA based assays to detect these resistance mechanisms. Detection of these genes is presently dependent on RNA based approaches using relatively sophisticated equipment (e.g. RTqPCR). Assays to detect the genetic mutation(s) responsible for the resistance phenotype in individual insects can provide an early warning of the emergence of resistance which may not have been detectable by bioassays that can only record the population response. The presence of a single individual with an allele known to confer resistance should be cause for concern as experience dictates that resistance can spread very rapidly in a population unless the selection pressure is eased and/or the genetic cost associated with the resistant allele is high. Conversely, a negative result from a molecular assay should not lead to complacency. As discussed above, molecular assays are presently only available for target site resistance and the failure to detect $k d r$ clearly cannot be interpreted as an absence of resistance in a population. Hence molecular assays should be seen as a complement rather than a substitute for bioassays. 


\section{Current distribution of insecticide resistance}

Insecticide resistance has been reported in the main malaria vectors worldwide. Resistance is however not uniformly distributed among vector species and can greatly differ from one village, province, country, region and continent to another. Unfortunately, the highest levels of insecticide resistance were reported in Africa where malaria burden is still the highest in the world [1]. Resistance to pyrethroids, the gold standard insecticides used for LLIN and IRS will be extensively discussed in the present chapter as it remains a real and ever-present danger to future success of malaria vector control. Note that more information on the distribution of insecticide resistance in malaria vectors can be found in Anobase, http://anobase.vectorbase.org/ir/; MARA http://www.mara.org.za; Arthropod Pesticide Resistance Database, http:// www.pesticideresistance.org.; and IR mapper, http://www.irmapper.com.

\subsection{Africa}

Although the occurrence of insecticide resistance in malaria vectors in Africa is not a "new" event (see section 2.), the speed at which pyrethroid-resistance recently evolved in field populations is worrying as it may jeopardize the current malaria vector control initiatives carried out in the continent. As shown in figure 2, pyrethroid resistance in Anopheles sp. is widespread but not uniformly distributed among the different countries. In the 49 African countries that have been investigated (see [6] for details), 15 did not report any data on resistance in the last 10 years i.e. Algeria, Botswana, Democratic Republic of Congo, Djibouti, Sierra Leone, Lesotho, Liberia, Libya, Maurice, Mauritania, Namibia, Rwanda, Somalia, Swaziland, Tunisia. If a lot of data has been generated in West Africa (as far as An. gambiae s.l. is concerned), a lack of information is globally observed in Central, Eastern and Austral Africa. It is obvious that the frequent conflicts that has occurred in the last decades in some African countries has rendered difficult the conduct of routine monitoring surveys by NMCP, International Organisation (WHO/ANVR) and/or research institutions.

Globally, pyrethroid resistance is high in An. gambiae s.l. in West Africa including Benin [127], Burkina Faso [128], Guinea Konakry ([129], Ghana [130], Mali [131], Niger [132], Nigeria [133] and Cote d'Ivoire [134]). In this region, pyrethroid resistance is predominant in An. gambiae s.s., compared to An. arabiensis. Surprisingly, susceptibility to pyrethroids (permethrin and/or deltamethrin) was reported in An. gambiae s.l. in Guinea Bissau [135] despite the presence of the L1014F mutation. In Central Africa, pyrethroid resistance/tolerance is widespread in An. gambiae s.l in Cameroon [136-138], Chad [116, 139], Gabon [140, 141], Equatorial Guinea [8] and Sudan $[142,143]$. In Chad, North Cameroon and Sudan, pyrethroid resistance is present essentially in An. arabiensis, which is consistent with the higher prevalence of this mosquito species in more arid areas with higher mean annual temperatures [144]. In East and Austral Africa, An. gambiae and An. arabiensis populations are mostly susceptible to pyrethroids in Tanzania [145, 146], Mozambique [147] and Madagascar [148], but highly resistant in eastern Uganda [149, 150], Ethiopia [151], Kenya [152, 153], Zambia [154], South Africa [155] and the Gwave Region of Zimbabwe [120]. Regarding An. funestus, most of the literature reporting pyrethroid resistance comes from South Africa [39, 156] and Mozambique [157-159], most probably because An. funestus is the main malaria vector in these countries. The data available 


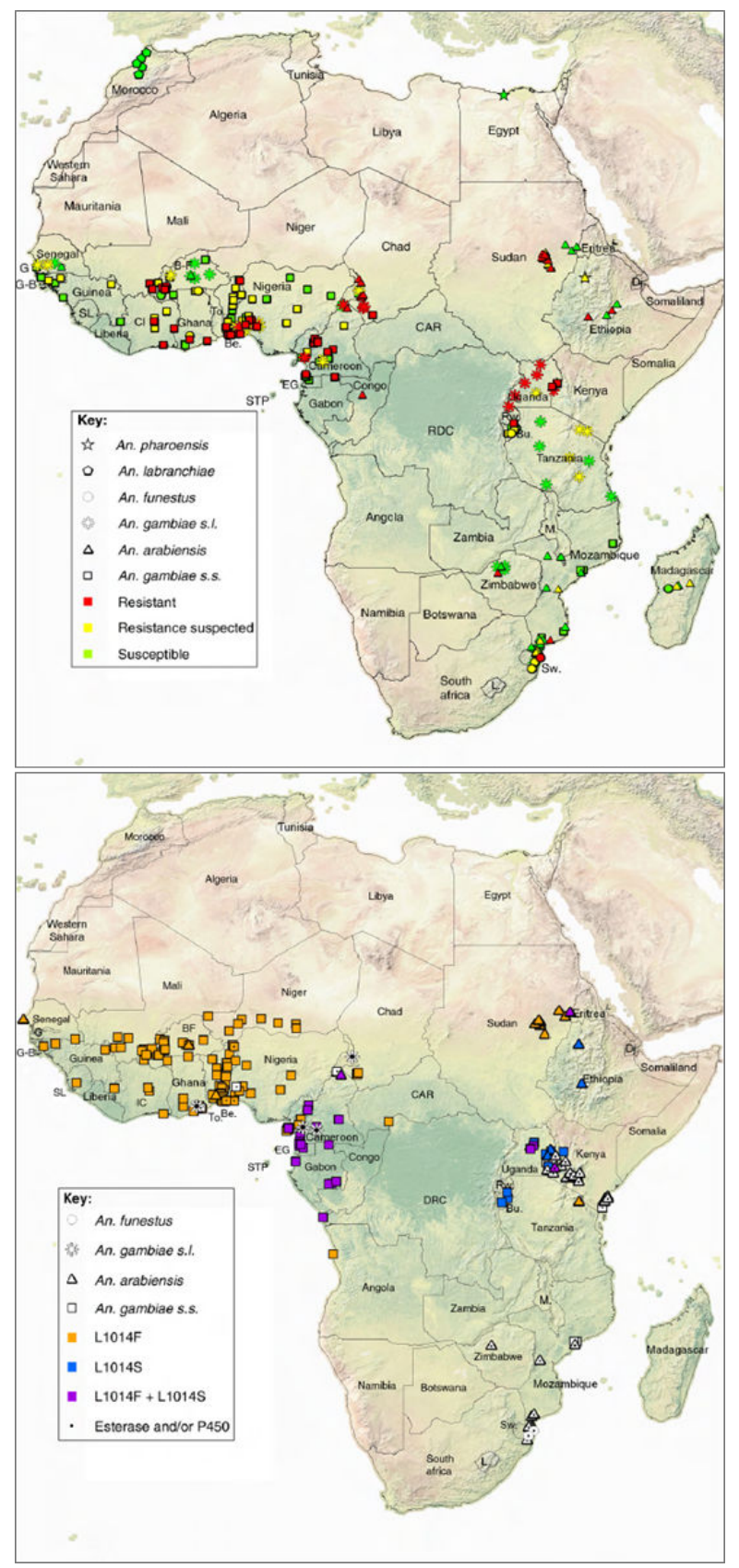

Figure 2. Maps showing the distribution of pyrethroid-resistance in African malaria vectors; A) status of pyrethroid resistance according to WHO criteria ; B) Target site $(k d r)$ and metabolic resistance reported for a given mosquito species (Source; see [6]). 
in other African countries is very limited in partly due to the difficulty to colonize $A n$. funestus species in laboratory. Pyrethroid resistance/tolerance was detected in Malawi [160, 161] and suspected in Obusi and Kassena-Nankana Regions from Ghana [121, 162] and Benin [163] whereas full susceptibility to permethrin and deltamethrin was found in Burkina Faso [164] and Tanzania [145]. There is a lack of information on secondary vectors e.g. An. moucheti and An. nili which can play important role in malaria transmission in specific settings (e.g. Cameroon, Congo, Côte d'Ivoire). Regarding other vectors species, full susceptibility to pyrethroids has been reported in An. labranchiae in Morocco [165] and in An. pharoensis in Egypt [166] and Ethiopia [167].

In Africa, the L1014F mutation is widespread (figure 2) and predominant in the molecular S form compared to the $\mathrm{M}$ form, except in Benin [168], Guinea Equatorial [8] and Niger [132]. Some authors suggested that the $k d r$ alleles may have arisen from at least four independent mutation events in the An. gambiae S-form [169]. Regarding the M form, it is not clear whether the $k d r$ mutation resulted from an introgression from the $S$ form only $[170,171]$ and/or from independent mutation events, has recently suggested for Bioko Island [172]. The second mutation, a leucine-serine substitution at the same codon (L1014S), was identified first in a colony of An. gambiae s.l. from Kenya [98]. This substitution has been lately reported in Burundi [173], Cameroon [136, 138], Gabon [174], Equatorial Guinea [175], Uganda [176], Republic of Congo [177] and Angola [140], mainly in co-occurrence with the 1014F $k d r$ allele. Although some authors have reported that the $1014 \mathrm{~S}$ allele may confer lower level of pyrethroid resistance than the $1014 \mathrm{~F}$ allele [178], its spread from eastern to central Africa and more recently to West Africa [124, 179] suggest a survival advantage of mosquitoes sharing this mutation in presence of pyrethroids. So far, the L1014S substitution has always been detected in the S molecular form [180] but recent findings showed the occurrence of the $1014 \mathrm{~S}$ allele in the M form in Equatorial Guinea [181] and Cameroon [182]. In these two countries, the 1014S allele was present at very low frequencies, alone or associated with the L1014F allele. It is currently impossible to know whether the $k d r$ alleles have arisen first in Cameroon or Equatorial Guinea. The higher frequency of the $1014 \mathrm{~S}$ allele in the $\mathrm{S}$ form compared with the $\mathrm{M}$ form could either be attributed to an introgression from the $S$ taxon or to a de novo mutation. Regarding the sister taxa An. arabiensis, both of these mutations were reported in Western [124], Central [183] and Eastern Africa [184]. Interestingly, a new $k d r$ mutation (N1575Y) occurring within domains IIIIV of voltage gate sodium channel was found in both $\mathrm{S}$ and M molecular forms of An. gambiae and occurs upon a 1014F haplotypic background only [100]. Additive resistance of $1575 \mathrm{Y}$ was demonstrated for permethrin and DDT in both molecular forms of An. gambiae. The prevalence of the $1575 \mathrm{Y}$ mutation has increased in West Africa in the last years hence indicating that the 1014F-1575Y haplotype is under strong selection pressure (Djégbé pers. com). It is possible that besides the $1014 \mathrm{~F} / 1014 \mathrm{~S} k d r$ mutation, other mutations in the para-type sodium channel gene might be needed for mosquitoes to survive after exposure to a discriminating concentration of an insecticide. Further investigation is needed to better address the distribution and the role of the N1575Y mutation in pyrethroid resistance as well as to assess the fitness benefits conferred by this allele on the L1014F mutation in malaria vectors.

Beyond the spread of $k d r$ alleles, metabolic-based resistance due to detoxifying enzymes namely oxidase, the GST (epsilon) and CCE families have expanded in African malaria vectors. 
In An. gambiae s.l. metabolic resistance involving increased levels of $\mathrm{P} 450$ has been reported at least in Kenya [185], Cameroon [186], Benin [69], Nigeria [69], Ghana [70], Mozambique [147], South Africa [187] and Zimbabwe [120]. Up to now, only genes encoding CYP6P3 and CYP6M2 P450 enzymes have been clearly involved in cellular mechanisms known to metabolize deltamethrin and permethrin [10, 71].These genes were found over-expressed in pyrethroidresistant An. gambiae populations from Benin, Nigeria and Ghana [69, 70], mainly in coassociation with the $k d r$ L1014F allele. In An. funestus, pyrethroid resistance involving increased activity of P450 monooxygenase and/or GST was demonstrated in South Africa [157], Mozambique [188] and Malawi [161].

To conclude, the immense challenge in Africa will be not to manage and control $k d r$-resistant mosquitoes only but to deal with the development of "multiple resistant" populations that could resist to different class of insecticides used in public health. One other issue is the occurrence and development of carbamate resistance in some countries (eg Benin, Nigeria) where this chemical class is in use for IRS through the PMI programme [47,48]. The spread of carbamate resistance in malaria vectors in Africa is worrying for insecticide resistance management and alternative insecticides, and innovative strategies are urgently needed to better reduce the vectorial capacity of mosquitoes and hence effectively reduce the burden of malaria in the region. Resistance management strategy for malaria control is discussed in section 8 .

\subsection{South-East Asia and India}

The South East Asia Region (SEAR) that account for 13\% of the total malaria cases worldwide ( $2^{\text {nd }}$ position after Africa) [1] is not spare of insecticide resistance in the main malaria vector species.

In the Mekong region, cross-country monitoring of insecticide resistance has been conducted through the MALVECASIA network (http://www.itg.be/malvecasia/) to help MCPs in the choice of insecticide to use at regional level. Large differences in insecticide resistance status were observed among species and countries. Anopheles dirus s.s., the main vector in forested malaria foci, was mainly susceptible to permethrin except in central Vietnam where it showed possible resistance to type II pyrethroids [23]. Anopheles minimus s.l. populations were found resistant / tolerant in Vietnam and northern Thailand [189] but almost susceptible in Cambodia and Laos. No $k d r$ mutation has been observed so far in these species [190] and pyrethroid resistance seems to result from increased detoxification by esterases and/or P450 monooxygenases [191]. Indeed, increased mRNA expression of two P450 genes, CYP6P7 and CYP6AA3, suspected to metabolize some pyrethroids [76] have been reported in a deltamethrin-resistant population of An. minimus in Thailand [75, 192].

Anopheles epiroticus of the Sundaicus Complex showed to be highly resistant to all pyrethroids in the Mekong Delta [23] but susceptible to DDT, except near Ho Chi Minh City. DDT and pyrethroid-resistant populations of An. subpictus were reported in Vietnam and Cambodia. Biochemical assays suggest an esterase-mediated pyrethroid detoxification in both $A n$. epiroticus and An. subpictus whereas DDT resistance in An. subpictus might be conferred to a higher GST activity. In Vietnam and Cambodia, An. vagus and An sinensis showed various 
levels of pyrethroid resistance and sequence-analysis of the DIIS6 region of the VGSC revealed the presence of the 1014S $k d r$ allele [193]. Pyrethroid resistant populations of An. sinensis were also reported in the Republic of Korea (ROK) [194] and in China [195]. In China, cypermethrin resistance in An. sinensis was associated with the presence of both $1014 \mathrm{~F}$ and L1014C substitutions, whereas only 1014F and 1014S mutations were found in the ROK and Vietnam, respectively. In Indonesia, molecular analysis carried out in field mosquito samples revealed the presence of the $1014 \mathrm{~F}$ allele in the four main malaria vectors i.e. An. sundaicus, An. aconitus, An. subpictus and An. vagus [196]. At the present time, it is difficult to speculate on the relative contribution of the $k d r$ mutations versus metabolic detoxification on pyrethroid and DDT resistance in malaria vectors from the SEA region and more work are needed to establish a clear trend.

Insecticide resistance is known to be widespread in other part of Asia such as India. In this country, resistance has a long history (see section 2) and it represents a big challenge for malaria vector control. Among the Anopheles species, An. culicifacies s.l., the major vector of malaria in most parts of the country, has developed strong resistance to pyrethroids [36], DDT [197, 198], dieldrin/HCH [199], and malathion [198]. The 1014F mutation, which generates the $k d r$ phenotype was detected in pyrethroid and DDT resistant An. culicifacies s.l. populations sometimes in co-occurrence with the $1014 S$ mutation [197]. Note that a novel mutation V1010L (resulting from G-to-T or -C transversions) in the VGSC was recently identified in Indian An. culicifacies and was tightly linked to 1014S substitution [197]. Elevated activities of GST seem to play also an important role in DDT-resistance in this mosquito species [82]. Similarly, strong level of pyrethroid resistance due to the presence of both 1014F and 1014S mutations was found in the urban malaria vector An. stephensi particularly in the Rajasthan District [200]. Other vectors that are reported to be resistant to pyrethroid, DDT and/or dieldrin/ $\mathrm{HCH}$ in India are An. annularis, An. subpictus and An. philippinensis [201]. In contrast, An. minimus has still not showed pyrethroid and DDT resistance [202].

The same trend was noted in Sri Lanka where the main malaria vectors species, i.e. An. culificifacies s.l. and An. subpictus have developed DDT, pyrethroid and malathion resistance in several districts [203, 204]. However, the main mechanisms associated with DDT and malathion resistance in An. culicifacies s.l. and An. subpictus are primarily metabolic and involve carboxylesterases (malathion) or monooxygenases and GSTs (for DDT) [205, 206]. An altered acetylcholinesterase conferring organophosphate resistance has been suspected in both vector species [205].

In the delta region of Bangladesh, the An. sundaicus malaria vector is fully susceptible to DDT but other malaria vectors such as An. philippinensis, An. maculatus s.l., and An. aconitus have all developed resistance to DDT [207]. Anopheles aconitus, additionally, has been reported to be resistant to dieldrin/HCH. Bhutan records An. maculatus s.l. as resistant to DDT, but there is no record of its resistance to any other insecticides [207]. Two vectors of malaria in Nepal, $A n$. maculatus s.l. and An. aconitus, also have developed resistance to DDT whereas only malathion resistance was reported in An. stephensi in Pakistan [208]. Finally, in Iran and Turkey, An. stephensi and An. sacharovi showed resistance to DDT and dieldrin but both species are mostly susceptible to pyrethroids [209-211]. 


\subsection{Latin America}

The countries of the Amazon Basin (Bolivia, Brazil, Colombia, Ecuador, Guyana, Peru, Surinam and Venezuela) carry the greatest burden of malaria in the Americas. The primary vectors of this disease in the Amazon basin are An. darlingi and An. albimanus. Surprisingly, much less data on insecticide resistance is available for these two mosquito species comparatively to African and/or Asian malaria vector species [212].

In Colombia, DDT resistance was reported in the late 80's in some populations of An. darlingi in the districts of Quibdó and close to the Atrato River [213, 214]. Successive insecticide susceptibility evaluations revealed resistance to pyrethroids in both An. darlingi and An. albimanus mainly in the Chocó State [215]. In An. darlingi, increased levels of both Multi function Oxidase (MFO) and Non specific Esterase (NSE) were reported in a deltamethrin and DDTresistant population, hence suggesting a possible involvement of these detoxifying enzymes in cross resistance to DDT and deltamethrin [35]. Note that various levels of resistance to organophosphate and pyrethroids were also reported in the secondary malaria vector $A n$. nuneztovari [216].

In neighboring countries, DDT, permethrin and deltamethrin resistance was found in laboratory colonized populations of An. albimanus from Guatemala, whereas full susceptibility was noted in field populations from El Salvador and Belize [217, 218]. The colonies from Guatemala showed significant increase in the specific activity of esterase and/or oxidase as measured by spectrophotometer suggesting their potential involvement in pyrethroid-resistance [34, 217]. In Peru, monitoring campaigns carried out since 2000 showed that An. albimanus was the only Anopheline species to exhibit pyrethroid-resistance [219].

In Mexico, high level of DDT resistance and low levels of resistance to organophosphate, carbamate and pyrethroid insecticides were detected in field populations of An. albimanus in Chiapas, prior to a large-scale resistance management project [220]. Biochemical assays revealed that the DDT resistance was caused by elevated levels of GST activity leading to increased rates of metabolism of DDT to DDE [22], whereas carbamate resistance was attributed to an altered acetylcholinesterase (AChE). More recent studies conducted in the southern Yucatan Peninsula showed high levels of DDT, deltamethrin and pirimiphos-methyl resistance in the An. albimanus populations tested [221]. Biochemical tests revealed elevated levels of GST, P450 and esterases activities that could be involved in DDT and pyrethroid-resistance. As for carbamate, pirimiphos-methyl resistance was strongly correlated with the presence of an insensitive acetylcholinesterase.

To our knowledge, it is the main "published" information available on the distribution, levels and mechanisms of resistance (i.e. accessible through Medline and pub med) in malaria vectors in Latin America. It is then essential to strengthen the capacity of all Latin America countries that suffering from malaria to make insecticide monitoring in routine to obtain much accurate information on the insecticide resistance situation in the malaria vectors. This will provide stake holders with useful information for the implementation of more effective and sustainable malaria control programmes in the region. 


\section{Impact of pyrethroid-resistance on programmatic malaria control}

Few operational reports exist that measure the impact of pyrethroid resistance on epidemiological outcomes of malaria, owing to body of factors that mislead the attributable component of resistance. Where tentative evidence is provided in most cases, the design of the study has been observational and the effect of confounding factors can never be excluded with confidence, making difficult the interpretation of data.

Most probably, the only clearest evidence of control failure being directly linked to pyrethroid resistance was reported from the borders of Mozambique and South Africa. In 1996, the malaria control programme in KwaZulu Natal switched from using DDT to deltamethrin for indoor spraying. Within four years, notified malaria cases had increased about four fold, An. funestus had re-appeared and was observable emerging alive from pyrethroid sprayed houses. Bioassays showed that this species was resistant to pyrethroids but susceptible to DDT [39]. A decision was taken to switch back to DDT spraying and, within the two years after this switch was made, An. funestus was no longer observed emerging alive from insecticide sprayed houses. The combination of DDT and antimalarial drugs in KwaZulu-Natal has resulted in a $91 \%$ decline in the malaria incidence rate $[222,223]$. There is no doubt that that the emergence of pyrethroid resistance and the avoidance of its effects by switching to DDT, has been of major operational importance [224].

Additional evidence was brought on the island of Bioko on the West African Coast. A malaria control strategy based on IRS with lambdacyhalothrin was launched by the Bioko Island Malaria Control Project (BIMCP) funded by the Government of Equatorial Guinea and a consortium of private donors led by Marathon Oil Corporation. One round of IRS using the pyrethroid deltamethrin (K-Orthrine WP50, Bayer Crop Sciences, Isando, South Africa) failed to curtail an increase in the population density of An. gambiae $\mathrm{M}$ form because of evidence in the rise of the knock-down resistance $(k d r)$ gene in this species [8]. The programme switched to carbamate insecticide before a substantial decline in the mosquito population, transmission index and malaria prevalence in children was seen. Nevertheless, in an observational study such as this, the possible contribution of other confounding factors to the failure of pyrethroid IRS cannot be overlooked so the direct consequence of the $k d r$ frequency is unclear.

Another programmatic study was conducted in the highland provinces of Burundi. Between 2002 and 2005, a well targeted vector control programme (conducted in foot of valleys only) combining IRS with pyrethroids and/or PermaNet 1.0 LLINs was initiated in one of the most affected island provinces, Karuzi [225]. Initially, one round per year of pyrethroid-IRS was carried out in all human dwellings and cattle sheds before the seasonal increase in transmission. LLIN distribution preceded the first IRS round in the same year. The S-form of An. gambiae was the predominant vector species in Karuzi District and showed resistance to pyrethroids due to the $k d r$ mutation. The entomological data showed that the intervention, overall, effectively reduced Anopheles density by $82 \%$ and malaria transmission was decreased by $90 \%$ despite high frequencies of the L1014S allele in the local An. gambiae population [173].

In a more recent observational study conducted in Malawi, the impact of pyrethroid resistance on operational malaria control has been assessed with more controversial evidence of 
resistance impacting pyrethroid-based vector control [161]. In this trial, pyrethroid-LLINs were distributed to communities in 2007 followed by a pilot campaign of IRS with lambdacyhalothrin supported by the President's Malaria Initiatives between 2008-2010 within districts. A series of sentinel sites were established during these periods to track the effect of the increase in pyrethroid resistance in the local malaria vectors (An. gambiae and An. funestus) and assess any impact on malaria transmission and prevalence of infection. Pyrethroid resistance had been selected over the 3 years of the programme in these two major malaria vectors with the resistance in the later vector (i.e; An. funestus) being metabolically-mediated and involving the up-regulation of two duplicated P450s. The selection of resistance over 3 years had however not triggered a major increase in parasite prevalence in Malawian children, but it may have reduced the benefit of introducing IRS alone in several districts [161]. The impact of this pyrethroid resistance on the ability of LLIN and IRS to reduce malaria infection in Malawi needs to be further elucidated.

Similarly, in the Dielmo Village of Senegal, a longitudinal study of inhabitants was carried out between January, 2007, and December, 2010 [226]. In July, 2008, deltamethrin-LLINs were provided to all villagers and asymptomatic carriage of malaria parasites was assessed from cross-sectional surveys. Overall, the incidence density of malaria attacks decreased from 5.45 per 100 person-months before LLINs distribution in 2007 to 0.41 by August 2010, but increased sharply back to 4.57 between September and December, 2010, i.e, in less than 3 years after the distribution of LLINs. Within the same time frame, the malaria vector became gradually resistant to pyrethroids and the prevalence of the $1014 \mathrm{~F} k d r$ resistance allele increased from scratch, i.e. $8 \%$ in 2007 to $48 \%$ in 2010 . Once again, these results should be considered with caution as the study was conducted in an unique village and the conclusions drawn could not be extrapolated or extended to Senegal or other areas of Western Africa. Moreover, the link between the slight rise of pyrethroid resistance and the rebound in malaria cases cannot be established with accuracy and such rebound could be due to other sources of factors totally independent of resistance.

Another recent study reports the presence of pyrethroid-resistance in malaria vectors versus the gain in current efforts to control malaria in the Zambia [154]. In line with the Global trend to improve malaria control efforts, a country wide campaign of Olyset Nets and PermaNets (LLIN) distribution was initiated in 1999 and indoor residual spraying with DDT or pyrethroids was reintroduced in 2000 in the country by the NMCP. In 2006, these efforts were strengthened by the PMI. Both major malaria vectors, An. gambiae and An. funestus were controlled effectively with the ITN and IRS programme in Zambia, maintaining a reduced disease transmission and burden, despite the discovery of DDT and pyrethroid resistance in the country.

There have been extensive randomized controlled trials (RCTs) (phase III) in part of Africa aiming at investigating the efficacy of ITNs for malaria prevention [227], but very few have assessed how pyrethroid resistance might affect the effectiveness of such intervention. RCTs entail a set of communities randomly divided into groups, one that receives the novel form of vector control intervention, and comparison arms that often receive the old form of vector control tools or nothing. The key difficulty is that it is impossible to address the question to 
whether vector control would produce a smaller reduction in malaria if the vector mosquitoes are resistant than it would have done if they were susceptible, using RCT methods. This is simply because resistance is not an easy factor that can be allocated randomly to some communities and not to others. The distribution of resistance is patchy and its severity seems to differ from one location (village) to another. Moreover there may be more resistance or survival trend of mosquitoes in some villages than others because of variations in the quality of vector control operations, or in mosquito behavior [228, 229]. This is important to mention, because many health scientists regard evidence from randomized-controlled studies as the only reliable basis for decision-making in public health.

The first RCT that investigated the impact of pyrethroid-resistance on LLIN efficacy was conducted in the Korhogo area in the north of Côte d'Ivoire. The trial encompassed multiple villages where the 1014F $k d r$ allele frequency was $>90 \%$ [28] and malaria was endemic. The regular use of conventionally lambdacyhalothrin-treated nets had a significant impact on the entomological inoculation rate (55\% reduction) and on malaria incidence in children $<5(56 \%$ reduction of clinical attacks) compared to a control group having no nets [230]. This was the first clear-cut evidence of ITNs continuing to provide effective personal protection against malaria in an area with a very high frequency of $k d r$ in the vector population. However, as reported in Ranson et al. [6], the absence of a physical barrier in the control group may have overestimated the impact of pyrethroid treated nets against $k d r$ mosquitoes in this study.

More recently, another RCT of LLINs and/or IRS was conducted in 28 villages in southern Benin, from 2007 to 2010 [231]. The objective of the study was to examine whether carbamateIRS applied every 8 months, as practiced by the PMI programme in Benin provided additional benefit over LLINs (ie Permanet 2.0) in term of malaria prevention and management of pyrethroid resistance in malaria vectors. Results showed that combination of LLINs and IRS did not reduce malaria transmission and morbidity compared to LLIN alone in an area of pyrethroid resistance [124]. Significant increase of 1014F $k d r$ frequency was observed in the reference and treated arms only 18 months post intervention hence indicating that LLIN and IRS failed to reduce the spread of the $1014 \mathrm{~F}$ allele in malaria vectors. The authors suggested that the increase in pyrethroid resistance might have accounted for the reduction of LLIN efficacy at a community level. Clearly, further investigation is needed to assess whether pyrethroid-resistance can reduce efficiency of LLINs and IRS for malaria prevention in Africa.

Given the many obstacles for evaluating the epidemiological impact of resistance, other alternative methods to measure operational impact has been to measure proxy entomological outcomes, such as the relative mortality and feeding success of resistant and susceptible vectors in experimental huts [232, 233]. Although such results can be remarkably clear, and definitively linked to resistance, experimental hut methods have their own limitations owing to the controlled hut structures that differ in many ways to normal houses in rural African context.

An early experimental hut trial of ITNs was conducted in the western African country of Benin. In southern Benin (Ladji), pyrethroid resistance has evolved in the $\mathrm{M}$ form of An. gambiae mosquitoes that appear to combine the knockdown resistance $(k d r)$ gene with oxidase mechanisms [127, 234]. In Ladji, carrier mosquitoes of this resistance were not controlled by pyrethroid treatments in experimental hut trials of ITNs or the leading brands of LLINs, PermaNet 2.0 (Vestergaard Frandsen SA, Aarhus, Denmark) and Olyset (Sumitomo Chemi- 
cals, Osaka, Japan) [235]), compared to Malanville in the north where the vector was largely susceptible to pyrethroids [127]. Further household randomized trial conducted in northern susceptible and southern resistance areas demonstrated that lambdacyalothrin-ITNs (regardless the physical condition) lose their capacity to confer personal protection against pyrethroidresistant An. gambiae [236].

One of the problems associated with many of these studies is that, due to the lack of molecular markers for alternative resistance mechanisms (i.e. metabolic or even cuticular and behavioral), the frequency of $k d r$ alleles is frequently used as a proxy for resistance. It has been recently demonstrated in Southern Benin that $k d r$ by itself in An. gambiae does not seem to bear more malaria parasites than in a susceptible [237] but this conception can be misleading when metabolic or other resistance mechanisms are predominant or combine with $k d r$ to confer resistance. There is an urgent need for properly controlled large-scale trials to assess the impact of pyrethroid resistance on IRS and ITNs in Africa but also in different regions affected by malaria (e.g. Asia and Latin America). Such studies should use both entomological and epidemiological indices and should be conducted in areas where alternative resistance mechanisms are known to be responsible for pyrethroid resistance. Furthermore, these studies must consider the possibility of behavioural resistance as recently suggested in Benin [238] and Tanzania [111] and monitor for changes in key traits such as location of resting and feeding which may impact on the efficacy of current insecticide based interventions.

\section{Resistance management strategies}

As a general statement, the use of insecticides does not create resistance by itself but select small proportion of individuals having a genetic mutation that allow them to resist and survive the effects of the insecticide. If this advantage is maintained by constant use of the same insecticide, the resistant insects will reproduce and the genetic changes that confer resistance will be transferred to offspring so that they become more prevalent within the population (figure 3). This selection process will take longer time to occur if the gene conferring resistance is rare or present at a low prevalence. Resistance should not be confused with "induction" that can occur after sub-lethal (or low dose) exposure to any insecticide and/or xenobiotic and is not passed on to offspring [239].

\subsection{Main factors influencing resistance development}

The evolution of insecticide resistance is complex and depends on several genetic, biological and operational factors [240-242]. The biological factors relate by the life cycle of the insect (e.g. rate of reproduction, number of generation/offspring, rate of migration and isolation, etc), while the genetic factors include the intrinsic characteristics of the resistant genes (e.g. mono versus polygenic resistance, dominance, fitness cost and gene interaction). Operational factors concern the treatment itself including the method and frequency of application, dosage and residual activity of the insecticides as well as insecticide coverage. 


\section{$S$ S S}

Resistance rare
Exposure to insecticide

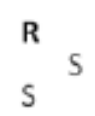

Resistance increasing

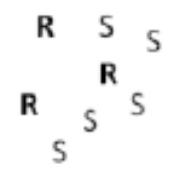

Survivors

reproduce

\section{Resistance common}

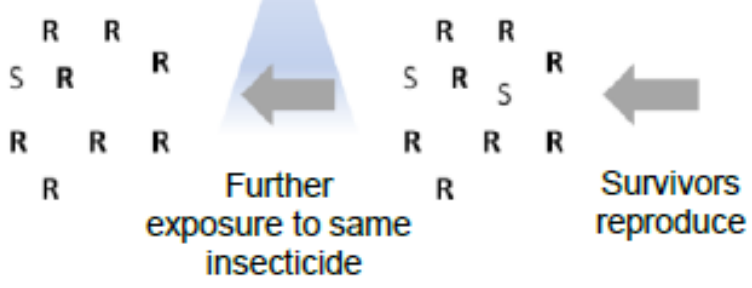

Figure 3. Possible scenario for resistance development in a mosquito population (source; [240])

\subsubsection{Biological factors}

\section{Rate of reproduction}

Insect species that have a short life cycle and high rates of reproduction are likely to develop resistance more rapidly than species that have a lower rate of reproduction, as any resistance genes can rapidly spread throughout the population. Because mosquitoes can produce high number of offspring (i.e. females can lay several hundred eggs during their reproductive life) they are much likely to develop resistance to insecticides than other species.

\section{Population migration / isolation}

With mosquitoes, the goal is to eliminate all or the majority of the population, however the greater the selection pressure that is put on a population, the faster susceptibility may be lost. Immigration of individuals possessing susceptible genes from untreated areas can beneficially dilute and compete with the resistance genes in the overall population. An early step in a malaria vector control programme should therefore be to estimate the susceptibility status of vector populations (see section 5 for details) and estimate potential immigration of untreated insects. This can be achieved by using genetic markers to estimate the gene flow (migrants) and genetic structure between populations. For example, an isolated area (e.g. island) where the entire area is treated would have a higher risk of developing resistance as few "susceptible" 
genotypes would join the treated population. The risk of insecticide resistance developing should be considered when planning a resistance management strategy. Awareness of and coordination with neighboring vector control programmes and agricultural activities should be encouraged, so that the regional and potential "side effect" on the target population is considered.

\subsubsection{Genetics factor}

\section{Dominance}

Resistance genes can range from dominant through semi-dominant to recessive. If dominant or semi-dominant, only one parent needs to possess the characteristic to be fully or partially expressed in the offspring. If recessive, both parents must possess the trait. Fortunately, most resistance mechanisms (e.g. $k d r$ ) are controlled by recessive or semi-recessive genes, which slows their spread within the population at early stage of resistance development when most individuals are present at heterozygous state. In contrast, when the resistance is genetically dominant, e.g. the Ace. $1^{R}$ gene conferring cross-resistance to carbamates and OPs [243], it can rapidly become established within the population and will be difficult to manage. Fortunately, strong genetic cost is often associated with dominant resistant gene that can compensate the effect of the dominance and slow down the increase of resistance gene frequency in natural populations [244].

\section{Gene interactions}

Epistasis is the non-additive interaction (synergistic versus antagonistic) between different loci which contribute to a phenotype [245]. Epistasis between independent loci conferring insecticide resistance is important to investigate as this phenomenon can shape the rate at which resistance evolves and can dictate the level of resistance in the field. Epistasis can be measured in laboratory studies on susceptible and resistant colonies, but without these data, it is generally impossible to predict whether or not it will occur when two genes are being evaluated. Studies of the interactions between resistance loci have been most commonly conducted in house flies [246-248]. Generally, a greater than additive interaction was observed between two loci that were both homozygous resistant, whereas additively (i.e. lack of epistasis) occurs between two loci that were both heterozygous. In mosquitoes, Harstone and colleagues [249] showed multiplicative interactions between $k d r$ and P450 detoxification in Culex pipiens quinquefasciatus whether the resistance alleles were homozygous or heterozyges. For example, resistance ratio 50 (i.e. LC50 resistant strain/LC50 susceptible strain) to permethrin in the double homozygote mosquitoes (RR50 of 30,000) was much higher than that expected (RR50 of 1,400) by simple additive effect of the two loci. Overall, interactions between independent resistant genes are complex. It is therefore important to better understand the interactions between resistant loci as well as to address how the fitness costs / benefits of the mechanisms can manipulate the observed interactions.

\section{Fitness cost}

Populations of insects that have never been exposed to insecticides are usually fully susceptible, and resistance genes within those populations are very rare. This usually occurs through 
a "fitness cost", which means that insects sharing the resistance allele lack some other attribute or "quality" such that it gives an advantage to the susceptible insects in an insecticide free environment [250]. For example, resistant insects may have lower mating success, be more susceptible to natural enemies [251], or more prone to mortality during over-wintering [252]. Increased production of metabolic enzymes generally shows lower associated fitness cost than those associated with alterations in the structural genes most probably because the primary function of the enzyme is not disrupted [253]. There is good laboratory and field evidence to suggest that the deficit of insecticide selection pressure, in most cases, selects for susceptible genotypes. For example, the absence of homozygote's resistant genotypes in An. gambiae populations in West Africa is most probably due to the strong genetic cost associated with the carbamate-resistance allele ace. $1^{R}$ (G119S) [254]. In addition, once resistance in the field has been selected it often rapidly reverts once the insecticide treatment regime is changed. A good example of this occurred in An. arabiensis in Sudan, where malathion specific insecticide resistance was selected in the early 1980s through antimalarial house spraying. The development of resistance prompted a switch of insecticide treatment to fenitrothion and the malathion resistance rapidly reverted in the following years. However, reversion rates are variable and may be very slow, particularly when an insecticide has been used for many years. For example, DDT was used extensively for malaria control over a 20 year period up to the 1960s in Sri Lanka to control An. culicifacies s.l. and An. subpictus. DDT was replaced by malathion in Sri Lanka in the early 1970s when a total and effective ban on DDT use was implemented. Subsequent regular monitoring has shown that DDT resistance has reverted very slowly towards susceptibility; around $80 \%$ of the adult mosquito population was resistant in the 1970 s compared to about $50 \%$ in the 1990s. The same is true with the $\mathrm{R} d l$ gene that was maintained in field mosquito populations despite the abandon of cyclodiene for mosquito control for more than 30 years [33]. Rate of reversion is an important parameter to consider before implementing any resistance management strategy in the field.

\subsubsection{Operational factors}

In practice, only operational factors such as the insecticide(s) used, the area of coverage (for example for IRS or LLIN), and the timing, rate, and method of application can be manipulated directly to reduce the selection pressure for resistance. Operational factors influence selection by determining the overall fraction of a population exposed (larvae/adults) to a selecting agent and the degree of contact and pick-up of toxicant by exposed pests at what has been termed the "interface between insects and insecticides" [242]. At both stages, operational and intrinsic factors interact in complex ways to establish the net effect of a control treatment on both genetic composition and total population size. Management of resistance therefore entails resolving these interactions to anticipate with some confidence both the suppressive and selective effects of potential control strategies.

Frequency of application, dosage and persistence of effect

How often an insecticide is used is one of the most important factors that influence resistance development [240]. With each use, an advantage is given to the resistant insects within a population. The rate of increase of resistance on any population will generally be faster in the 
presence of a lower fitness cost and high reproductive and short life cycles producing several generations per season. The length of time that an insecticide remains effective, also called its persistence, is dependent upon the physical chemistry of the insecticide, the type of formulation, the application rate and the substrate. Products which provide a persistent effect provide continual selection pressure in a similar manner to multiple treatments. For example, a space spray will persist for a very short time and will select only against a single generation of mosquitoes. In contrast, a residual wall application (IRS) or Insecticide Treated nets treatment (especially Long Lasting Nets) will persist for months or years providing a selection pressure against many generations of the same insect. For example, repeated application of DDT for indoor residual spraying has contributed to increase the number of DDT-resistant malaria vector species in various geographical settings [255]. Several studies showed however that the use of insecticides in agriculture play a key role in the selection of resistance in mosquitoes $[256,257]$. Indeed, most insecticides used in agriculture are of the same chemical classes and have the same targets and modes of action as those used in public health programme. In practice, VC programmes cannot influence the choice of the pesticide used for crop protection and the only thing that can be done is to appropriately select the most judicious insecticide for mosquito control. However, there is more published evidence that public health insecticides can contribute to select for pyrethroid resistance alleles (see section 7 for details). It is obvious that we can expect enhanced selection pressure on resistance genes through the scaling up of LLIN and/or IRS for malaria elimination.

\section{Choice of the insecticide}

The speed at which an insecticide effectively kills an insect can also influence the evolution of resistance. All current insecticides approved for ITNs or IRS kill extremely rapidly after contact. While fast-acting conventional insecticides can produce even more effective initial control, they impose enormous selection for resistance by killing young female adults. The consequence is that spectacular initial mosquito control can last as little as a few years, thus providing very poor medium- to long-term disease control [258]. Some authors recently suggest that Late Acting insecticides (e.g. entomofungus) may be a more tactical strategy to manage resistance if female mosquitoes are killed after 2 or more gonotrophic cycles [259]. Indeed, the less the insecticide impact on mosquito fitness, the less the strength of selection, especially if the resistance allele is associated with a strong genetic cost. In theory, it would be possible to create an insecticide that would provide effective malaria control yet never be undermined by the evolution of resistant mosquitoes. However, further studies are required as "proof of principle" i.e. to demonstrate that this strategy can be effective for vector management and malaria prevention in a real setting.

\subsection{Resistance management - Strategies and tactics}

Historically, the practice of using an insecticide until resistance becomes a limiting factor has rapidly eroded the number of suitable/available insecticides for vector control. Rotations, mosaics, and mixtures have all been proposed as resistance management tools [260, 261] but there are very few "success stories" in public health. Numerous mathematical models have been produced to estimate how these tools could be optimally used [262-264] but these models 
have rarely been tested under field conditions due to the practical difficulties in estimating changes in resistance gene frequencies (especially for metabolic resistance) in large samples of insects [220]. With the advent of different molecular techniques for resistance-gene frequency estimation, field trials of resistance management strategies have now become more feasible.

\subsubsection{Approaches to resistance management}

Ideally insecticide resistance management should be undertaken using insecticide based approaches in conjunction with other non-insecticidal vector control methods, i.e. as part of Integrated Vector Management (IVM $\left.{ }^{4}\right)$ [265]. The insecticides used have to be safe to humans and comply with WHO specifications. In practice, most of IVM programmes work well in experimental trials but become challenging when programmes are scaling up into long-term (operational) control. Operationally, the simplest form of resistance management is likely to be "insecticide" based, and this could take several forms.

\section{Rotations}

Rotational strategies are based on the rotation over time of two or preferably more insecticide classes with different modes of action. This approach assumes that if resistance to each insecticide is rare, then multiple resistances will be extremely rare [266]. Rotation allows any resistance developed to the first insecticide to decline over time when the second insecticide class is introduced. As for other strategy, rotations are particularly effective if the resistance gene has an associated fitness cost. The timeframe for rotation needs to be sufficiently short to prevent significant levels of resistance to develop to any one rotation partner. Rotations have been successful in many applications in agriculture and are considered to be effective in slowing the evolution of resistance (see [240] for details). The most striking example of "success story" using this strategy was within the framework of the Onchocerciasis Control Programme (OCP) carried in West Africa 40 years ago. Indeed, weekly application of unrelated larvicides in rivers was successful to kill the larvae of the blackfly vector and mitigate the spread of temephos resistance over the 17 years of its implementation [267]. However, the rotation was introduced at early stage of the OCP, as soon as the operators faced temephos resistance problems in pilot localities. As for all IRM strategies, the status of resistance of the insecticide used in the rotation must be known when implementing rotations and the chemicals used should not present any (known) cross-resistance. For LLIN, it is difficult to implement this method knowing that only pyrethroids are recommended so far by WHO for the impregnation [268]. For IRS, the pragmatic approach would be to rotate insecticides annually. Indeed, changing insecticides more than once a year (which could be the case in areas where two spray rounds are conducted each year) is not recommended, because of procurement and other financial and logistical challenges (see [4]). Despite higher cost of implementing rotation than single spray (as available alternatives to pyrethroids - the carbamates organophosphates, insect growth regulators, pyroles - are currently more expensive), this is probably the price to pay to preserve the arsenal of cost-effective insecticides for malaria vector control.

4Integrated Vector Management can be defined as "a rational decision making process for the optimal use of resources for vector control". IRM is therefore an integral part of IVM, as only through the active management of insecticide resistance can the available resources be optimally and sustainably used. 


\section{Mosaics}

Spatially separated applications of different compounds against the same insect constitute a "mosaic" approach to resistance management [240]. Fine scale mosaics can be achieved in malaria vector control programmes, for example, by using two insecticides in different dwellings within the same village. The aim of this strategy is to preserve susceptibility by spatial restriction of insecticides [4]. If such a fine scale mosaic is to be used, careful records of which insecticide was used in each house are essential. Larger scale mosaics have been shown to be effective for the management of pyrethroid resistance in An. albimanus in Mexico [22]. Indeed, pyrethroid resistance rose more rapidly in the areas under pyrethroid treatment alone than in the mosaic areas using OP, Pyrethroid and carbamate [240]. Whilst there are some practical difficulties implementing a mosaic in a vector control programme (eg spray with different insecticides, dosages, apparatus, etc), it may offer the advantages of a mixture strategy with lower insecticide inputs and hence cost. The scale at which a mosaic needs to be applied has not been clearly established. In South Africa for example, different insecticides have been used in different types of houses within the same community and this is considered by some to be a mosaic-like strategy [240]. Similarly, mosquito bed nets from panels treated with different insecticides achieve a similar mosaic effect to treating houses with different compounds but on a much finer scale. Industry has recently developed mosaic LLINs containing a pyrethroid insecticide and a synergist (Piperonyl butoxide or PBO an oxidase inhibitor) on the roof to increase efficacy against pyrethroid-resistant malaria vectors. Small scale field trial $[235,269]$ and mathematical exercises [270] suggested that mosaic LLIN may provide better insecticidal effect against resistant mosquitoes and enhanced community-level protection against malaria compared to "classical" LLIN in area of pyrethroid resistance. Clearly further operational research is required to establish the applicability and effectiveness of mosaics approaches for malaria control.

\section{Mixtures}

A mixture is defined by the simultaneous use of two or more insecticides of unrelated mode of action. If two insecticides $\mathrm{A}$ and $\mathrm{B}$, with independent resistance mechanisms, are applied together in a mixture, and if resistance to $A$ and resistance to B are both rare, then we expect doubly resistant insects to be extremely rare, and almost all insects resistant to A will be killed by B, and vice versa [266]. This system of "redundant killing" means that resistance to the two insecticides will evolve much more slowly than if either had been used on its own [271]. This approach may be not successful if resistance to one of the components used is already present at a detectable level and/or if linkage disequilibrium is present in the targeted population [4]. Unlike rotations, the effectiveness of mixtures is not directly related to the degree of fitness cost. Rather the mixture aims to overpower resistance instead of preserving susceptibility. However, for mixtures to work well in practice both insecticides need to be used at their full application rate in order that the efficacy and persistence of the two insecticides would be broadly similar (same decay rate). Further, theoretical models suggest that mixtures might delay resistance longer than rotations or broad mosaics [271, 272]. However, mixtures of products were rarely adopted in malaria vector control programmes on grounds of cost, logistics, and safety issue and because of the limited number of recommended compounds available for both 
IRS and LLIN. It is not yet clear however how much the addition of a second active ingredient will add to the total cost of manufacturing since the cost of additional insecticide can greatly vary according to the strategy, ie. cost for LLINs would be much lower than that for IRS. For LLIN, previous laboratory and field trials showed interesting prospects for reducing mosquito survival and biting rates with the use of insecticide mixtures applied on mosquito nets against $k d r$-resistant An. gambiae in Africa [273, 274]. Other chemicals, such as insect growth regulators (IGR), represent also promising alternative to be included in mixture formulations as they may impact on mosquito longevity, fertility and fecundity [275, 276]. With the development of next-generation of LLIN, combined use of non-pyrethroids and pyrethroids on bed nets is technically achievable and has the potential to provide better control of malaria and prevent further development of pyrethroid-resistance in malaria vectors. Risk assessment and acceptability of such new tools should be however carefully investigated before any trial being implemented at operational level.

\section{Combinations}

In this context, combinations expose the vector population to two vector control tools, such that a mosquito that survives contact with one (e.g. LLIN) is exposed to the other one (e.g. IRS), or vice versa. In practice, exposure to two insecticides is not guaranteed but there is some evidence to indicate that this is likely [277]. The effectiveness of combinations in IRM does not depend on the ability to reduce the level of resistance, but on the ability to kill the vector despite the existence of resistance, through the use of another insecticide or intervention, which compensates for resistance [231]. As for other strategy, the combination should not contain insecticides with same mode of action (e.g. avoid pyrethroids for both IRS and LLINs), as this would increase selection pressure rather than reducing it. As combinations require doubling of interventions, cost would be significantly higher than rotations and mosaics. This might nevertheless be warranted in some circumstances, for example where malaria transmission is very high and/or where targeted IRS can help overcome identified resistance to pyrethroids in areas with high LLIN coverage. In practice, combinations would be more easily implemented in countries having sufficient human and financial resources allocated to public health programmes. So far, a small number of observational studies [278-280] and mathematical modeling exercises $[263,264]$ suggest that VC combination has an added benefit for reduction of the risk of infection because the people not protected by one of the interventions are protected by the other. A recent cluster randomized controlled trial carried out in Benin showed however that neither clinical malaria in children younger than 6 years nor transmission intensity differ between LLIN and carbamate-IRS or Carbamate Treated Plastic Sheeting and the reference group (LLIN alone) and the insecticide combinations did not slow down the evolution of the $k d r$ allele in An gambiae s.s. compared with LLIN [231]. It was concluded from this study that IRS should be timely implemented (i.e. using appropriate insecticide, dosage and time interval) to ensure optimum efficacy of the IRS intervention over LLIN. Clearly, costeffectiveness of combined vector control interventions need to be carefully considered to ensure that increased efforts and cost dedicated to combinations effectively contribute to better control and management of pyrethroid-resistant malaria vectors. 


\section{Conclusions}

Insecticide resistance develops in an insect population when individuals carrying genes that allow them to survive exposure to the insecticide pass these genes on. Thus, any activities that control the individuals with the resistance trait will delay the spread of the resistance genes in the population. IRM should then be seen in the context of IVM and should therefore also include activities such as habitat management, community education, and/or larval source management (e.g. biological control). In order to successfully develop and implement any resistance management strategies based on rotations, mosaics, mixtures or combinations, knowledge of the mode of action, chemical properties, and residual life of the available insecticide products is essential. Although insecticides with novel modes of action have recently been introduced in public health (neonicotinoids, pyroles, oxadiazin, etc) few of them appear to have the optimum biological and/or physical properties required for residual wall spray and/or mosquito net. Unfortunately, the exorbitant costs associated with developing and registering new insecticides (see [281] for details) mean that products appear in the more profitable agricultural markets before consideration is given to their public health potential. We have then no other option than to make an appropriate and judicious use of the current insecticides if we want to avoid any disillusion with pyrethroids as we faced before with DDT or dieldrin. The philosopher George Santayana said "those who cannot remember the past are condemned to repeat it." Hope it's not too late for malaria vector control.

\section{Author details}

Vincent Corbel ${ }^{1,2^{*}}$ and Raphael N'Guessan ${ }^{3,4}$

*Address all correspondence to: vincent.corbel@ird.fr

1 Institut de Recherche pour le Développement, Maladies Infectieuses et Vecteurs, Ecologie, Génétique, Evolution et Contrôle (IRD 224-CNRS 5290 UM1-UM2), Benin

2 Department of Entomology, Kasetsart University, Bangkok, Thailand

3 London School of Hygiene \& Tropical Medicine, London, UK

4 Centre de Recherches Entomologiques de Cotonou, Cotonou, Benin

\section{References}

[1] World Health Organization: WHO malaria report : 2011. In: WHO Global Malaria Programme. Edited by Data WLC-i-P. Geneva: WHO; 2011: 259.

[2] Yassine H, Osta MA: Anopheles gambiae innate immunity. Cell Microbiol, 12(1):1-9. 
[3] Davidson G: Insecticide resistance in Anopheles sundaicus. Nature 1957, 180(4598): 1333-1335.

[4] World Health Organization: Global Plan for Insecticide Resistance Management in Malaria Vectors (GPIRM). In: WHO/HTM/GMP/20125. Edited by Organization WH. Geneva, Switzerland: World Health Organization; 2012: 130.

[5] Hemingway J, Ranson H: Insecticide resistance in insect vectors of human disease. Annu Rev Entomol 2000, 45:371-391.

[6] Ranson H, N'Guessan R, Lines J, Moiroux N, Nkuni Z, Corbel V: Pyrethroid resistance in African anopheline mosquitoes: what are the implications for malaria control? Trends Parasitol 2011, 27(2):91-98.

[7] Ridl FC, Bass C, Torrez M, Govender D, Ramdeen V, Yellot L, Edu AE, Schwabe C, Mohloai P, Maharaj R et al: A pre-intervention study of malaria vector abundance in Rio Muni, Equatorial Guinea: their role in malaria transmission and the incidence of insecticide resistance alleles. Malar J 2008, 7:194.

[8] Sharp BL, Ridl FC, Govender D, Kuklinski J, Kleinschmidt I: Malaria vector control by indoor residual insecticide spraying on the tropical island of Bioko, Equatorial Guinea. Malar J 2007, 6:52.

[9] Mitchell SN, Stevenson BJ, Muller P, Wilding CS, Egyir-Yawson A, Field SG, Hemingway J, Paine MJ, Ranson H, Donnelly MJ: Identification and validation of a gene causing cross-resistance between insecticide classes in Anopheles gambiae from Ghana. Proc Natl Acad Sci U S A 2012, 109(16):6147-6152.

[10] Stevenson BJ, Bibby J, Pignatelli P, Muangnoicharoen S, O'Neill PM, Lian LY, Muller P, Nikou D, Steven A, Hemingway J et al: Cytochrome P450 6M2 from the malaria vector Anopheles gambiae metabolizes pyrethroids: Sequential metabolism of deltamethrin revealed. Insect Biochem Mol Biol 2011, 41(7):492-502.

[11] Brown AWA: Insecticide Resistance Mosquitoes: A Pragmatic Rewiew. J Am Mosq Control Assoc 1986, 2(2):123-140.

[12] Metcalf RL: Insect resistance to insecticides. Pesticide Science 1989, 26(4):333-358.

[13] WHO: Global Insecticide Use for Vector-Borne Disease Control- 4th edition. In Edited by World Health Organization Geneva: World Health Organization 2009, WHO/HTM/NTD/WHOPES/GCDPP/2009.6.

[14] Lapied B, Pennetier C, Apaire-Marchais V, Licznar P, Corbel V: Innovative applications for insect viruses: towards insecticide sensitization. Trends Biotechnol 2009, 27(4):190-198.

[15] Livadas GA, Georgopoulos G: Development of resistance to DDT by Anopheles sacharovi in Greece. Bull World Health Organ 1953, 8(4):497-511. 
[16] Brown AWA, Haworth J, Zahar AR: Malaria eradication and control from a global standpoint. Journal of Medical Entomology 1976, 13(1):1-25.

[17] Patel TB, Ramachandra Rao T, Halgeri AV, Deobhankar RB: A preliminary note on a probable case of dieldrin kesistance in Anopheles culicifacies in Thana District, Bombay State. Indian J Malariol 1958, 12:367-370.

[18] Brown AW, Pal R: Insecticide resistance in arthropods. Public Health Pap 1971, 38(0): 1-491.

[19] Brown AW, Haworth J, Zahar AR: Malaria eradication and control from a global standpoint. J Med Entomol 1976, 13(1):1-25.

[20] Rajagopal R: Malathion resistance in Anopheles culicifacies in Gujarat. Indian J Med Res 1977, 66(1):27-28.

[21] Rawlings P, Herath PR, Kelly S: Anopheles culicifacies (Diptera: Culicidae): DDT resistance in Sri Lanka prior to and after cessation of DDT spraying. J Med Entomol 1985, 22(4):361-365.

[22] Penilla RP, Rodriguez AD, Hemingway J, Torres JL, Arredondo Jimenez JI, Rodriguez $\mathrm{MH}$ : Resistance management strategies in malaria vector mosquito control. Baseline data for a large-scale field trial against Anopheles albimanus in Mexico. Medical and Veterinary Entomology 1998, 12(3):217-233.

[23] Van Bortel W, Trung HD, Thuan le K, Sochantha T, Socheat D, Sumrandee C, Baimai V, Keokenchanh K, Samlane P, Roelants P et al: The insecticide resistance status of malaria vectors in the Mekong region. Malar J 2008, 7:102.

[24] Trung HD, Van Bortel W, Sochantha T, Keokenchanh K, Quang NT, Cong LD, Coosemans M: Malaria transmission and major malaria vectors in different geographical areas of Southeast Asia. Trop Med Int Health 2004, 9(2):230-237.

[25] Chareonviriyaphap T, Aum-aung B, Ratanatham S: Current insecticide resistance patterns in mosquito vectors in Thailand. Southeast Asian J Trop Med Public Health 1999, 30(1):184-194.

[26] Hamon J, Subra R, Sales S, Coz J: [Presence in the southwestern part of Upper Volta of a population of Anopheles gambiae "A" resistant to DDT]. Med Trop (Mars) 1968, 28(4):521-528.

[27] Carnevale P, Robert V: Anopheles: Biologie, transmission du Plasmodium et lutte antivectorielle. Bondy: IRD; 2009.

[28] Chandre F, Darriet F, Manguin S, Brengues C, Carnevale P, Guillet P: Pyrethroid cross resistance spectrum among populations of Anopheles gambiae s.s. from Cote d'Ivoire. J Am Mosq Control Assoc 1999, 15(1):53-59. 
[29] Armstrong JA, Ramsdale CD, Ramakrishna V: Insecticide resistance in Anopheles gambiae Giles in Western Sokoto, Northern Nigeria. Ann Trop Med Parasitol 1958, 52(3):247-256.

[30] Hamon J, Garrett-Jones C: [Resistance to insecticides in the major malaria vectors and its operational importance]. Bull World Health Organ 1963, 28(1):1-24.

[31] Wondji CS, Dabire RK, Tukur Z, Irving H, Djouaka R, Morgan JC: Identification and distribution of a GABA receptor mutation conferring dieldrin resistance in the malaria vector Anopheles funestus in Africa. Insect Biochem Mol Biol 2011, 41(7):484-491.

[32] Mouchet J: Mini-Review : Agriculture and Vector Resistance. Insect Sci Applic 1988, 9(3):291-302.

[33] Mahande AM, Dusfour I, Matias JR, Kweka EJ: Knockdown Resistance, rdl Alleles, and the Annual Entomological Inoculation Rate of Wild Mosquito Populations from Lower Moshi, Northern Tanzania. J Glob Infect Dis 2012, 4(2):114-119.

[34] Brogdon WG, McAllister JC, Corwin AM, Cordon Rosales C: Oxidase-based DDTpyrethroid cross-resistance in Guatemalan Anopheles albimanus. Pesticide Biochemistry and Physiology 1999, 64(2):101-111.

[35] Fonseca-Gonzalez I, Quinones ML, McAllister J, Brogdon WG: Mixed-function oxidases and esterases associated with cross-resistance between DDT and lambda-cyhalothrin in Anopheles darlingi Root 1926 populations from Colombia. Mem Inst Oswaldo Cruz 2009, 104(1):18-26.

[36] Raghavendra K, Verma V, Srivastava HC, Gunasekaran K, Sreehari U, Dash AP: Persistence of DDT, malathion \& deltamethrin resistance in Anopheles culicifacies after their sequential withdrawal from indoor residual spraying in Surat district, India. Indian J Med Res 2010, 132:260-264.

[37] Tiwari S, Ghosh SK, Ojha VP, Dash AP, Raghavendra K: Reduced susceptibility to selected synthetic pyrethroids in urban malaria vector Anopheles stephensi: a case study in Mangalore city, South India. Malar J 2010, 9:179.

[38] Elissa N, Mouchet J, Riviere F, Meunier JY, Yao K: Resistance of Anopheles gambiae s.s. to pyrethroids in Cote d'Ivoire. Ann Soc Belg Med Trop 1993, 73(4):291-294.

[39] Hargreaves K, Koekemoer LL, Brooke BD, Hunt RH, Mthembu J, Coetzee M: Anopheles funestus resistant to pyrethroid insecticides in South Africa. Medical and Veterinary Entomology 2000, 14(2):181-189.

[40] Chareonviriyaphap T, Rongnoparut P, Juntarumporn P: Selection for pyrethroid resistance in a colony of Anopheles minimus species A, a malaria vector in Thailand. J Vector Ecol 2002, 27(2):222-229. 
[41] Ayad H, Georghiou GP: Resistance to organophosphates and carbamates in Anopheles albimanus based on reduced sensitivity of acetylcholinesterase. Journal of Economic Entomology 1975, 68(3):295-297.

[42] Hemingway J: Genetics of organophosphate and carbamate resistance in Anopheles atroparvus (Diptera: Culicidae). J Econ Entomol 1982, 75(6):1055-1058.

[43] Elissa N, Mouchet J, Riviere F, Meunier JY, Yao K: [Susceptibility of Anopheles gambiae to insecticides in the Ivory Coast]. Sante 1994, 4(2):95-99.

[44] N'Guessan R, Darriet F, Guillet P, Carnevale P, Traore-Lamizana M, Corbel V, Koffi AA, Chandre F: Resistance to carbosulfan in Anopheles gambiae from Ivory Coast, based on reduced sensitivity of acetylcholinesterase. Med Vet Entomol 2003, 17(1): 19-25.

[45] Dabire KR, Diabate A, Namontougou M, Djogbenou L, Kengne P, Simard F, Bass C, Baldet T: Distribution of insensitive acetylcholinesterase (ace-1R) in Anopheles gambiae s.l. populations from Burkina Faso (West Africa). Trop Med Int Health 2009, 14(4): 396-403.

[46] Djogbenou L, Dabire R, Diabate A, Kengne P, Akogbeto M, Hougard JM, Chandre F: Identification and geographic distribution of the ACE-1R mutation in the malaria vector Anopheles gambiae in south-western Burkina Faso, West Africa. Am J Trop Med Hyg 2008, 78(2):298-302.

[47] Djogbenou L, Pasteur N, Akogbeto M, Weill M, Chandre F: Insecticide resistance in the Anopheles gambiae complex in Benin: a nationwide survey. Med Vet Entomol 2011, 25(3):256-267.

[48] Oduola AO, Idowu ET, Oyebola MK, Adeogun AO, Olojede JB, Otubanjo OA, Awolola TS: Evidence of carbamate resistance in urban populations of Anopheles gambiae s.s. mosquitoes resistant to DDT and deltamethrin insecticides in Lagos, South-Western Nigeria. Parasit Vectors 2012, 5:116.

[49] USAID: The President's Malaria Initiative: fourth annual report. In. Washigton: U.S. Agency for International Development; 2010.

[50] Nkya TE, Akhouayri I, Kisinza W, David JP: Impact of environment on mosquito response to pyrethroid insecticides: Facts, evidences and prospects. Insect Biochem Mol Biol 2012.

[51] Despres L, David JP, Gallet C: The evolutionary ecology of insect resistance to plant chemicals. Trends Ecol Evol 2007, 22(6):298-307.

[52] Hemingway J, Hawkes NJ, McCarroll L, Ranson H: The molecular basis of insecticide resistance in mosquitoes. Insect Biochem Mol Biol 2004, 34(7):653-665.

[53] Guillemaud T, Makate N, Raymond M, Hirst B, Callaghan A: Esterase gene amplification in Culex pipiens. Insect Molecular Biology 1997, 6(4):319-327. 
[54] Hawkes NJ, Hemingway J: Analysis of the promoters for the beta-esterase genes associated with insecticide resistance in the mosquito Culex quinquefasciatus. Biochim Biophys Acta 2002, 1574(1):51-62.

[55] Vaughan A, Hawkes N, Hemingway J: Co-amplification explains linkage disequilibrium of two mosquito esterase genes in insecticide-resistant Culex quinquefasciatus. Biochem J 1997, 325 ( Pt 2):359-365.

[56] Herath PR, Miles SJ, Davidson G: Fenitrothion (OMS 43) resistance in the taxon Anopheles culicifacies Giles. J Trop Med Hyg 1981, 84(2):87-88.

[57] Hemingway J: The genetics of malathion resistance in Anopheles stephensi from Pakistan. Trans $R$ Soc Trop Med Hyg 1983, 77(1):106-108.

[58] Vontas J, Blass C, Koutsos AC, David JP, Kafatos FC, Louis C, Hemingway J, Christophides GK, Ranson H: Gene expression in insecticide resistant and susceptible Anopheles gambiae strains constitutively or after insecticide exposure. Insect Mol Biol 2005, 14(5):509-521.

[59] Somwang P, Yanola J, Suwan W, Walton C, Lumjuan N, Prapanthadara LA, Somboon P: Enzymes-based resistant mechanism in pyrethroid resistant and susceptible Aedes aegypti strains from northern Thailand. Parasitol Res 2011, 109(3):531-537.

[60] Feyereisen R, Lawrence IG, Kostas I, Sarjeet SG: Insect Cytochrome P450. In: Comprehensive Molecular Insect Science. Amsterdam: Elsevier; 2005: 1-77.

[61] Holt RA, Subramanian GM, Halpern A, Sutton GG, Charlab R, Nusskern DR, Wincker P, Clark AG, Ribeiro JM, Wides $\mathrm{R}$ et al: The genome sequence of the malaria mosquito Anopheles gambiae. Science 2002, 298(5591):129-149.

[62] Ranson H, Nikou D, Hutchinson M, Wang X, Roth CW, Hemingway J, Collins FH: Molecular analysis of multiple cytochrome P450 genes from the malaria vector, Anopheles gambiae. Insect Mol Biol 2002, 11(5):409-418.

[63] Nikou D, Ranson H, Hemingway J: An adult-specific CYP6 P450 gene is overexpressed in a pyrethroid-resistant strain of the malaria vector, Anopheles gambiae. Gene 2003, 318:91-102.

[64] David JP, Strode C, Vontas J, Nikou D, Vaughan A, Pignatelli PM, Louis C, Hemingway J, Ranson H: The Anopheles gambiae detoxification chip: a highly specific microarray to study metabolic-based insecticide resistance in malaria vectors. Proc Natl Acad Sci U S A 2005, 102(11):4080-4084.

[65] Irving H, Riveron JM, Ibrahim SS, Lobo NF, Wondji CS: Positional cloning of rp2 QTL associates the P450 genes CYP6Z1, CYP6Z3 and CYP6M7 with pyrethroid resistance in the malaria vector Anopheles funestus. Heredity (Edinb) 2012, 109(6):383-392. 
[66] Chiu TL, Wen Z, Rupasinghe SG, Schuler MA: Comparative molecular modeling of Anopheles gambiae CYP6Z1, a mosquito P450 capable of metabolizing DDT. Proc Natl Acad Sci U S A 2008, 105(26):8855-8860.

[67] McLaughlin LA, Niazi U, Bibby J, David JP, Vontas J, Hemingway J, Ranson H, Sutcliffe MJ, Paine MJ: Characterization of inhibitors and substrates of Anopheles gambiae CYP6Z2. Insect Mol Biol 2008, 17(2):125-135.

[68] Muller P, Chouaibou M, Pignatelli P, Etang J, Walker ED, Donnelly MJ, Simard F, Ranson H: Pyrethroid tolerance is associated with elevated expression of antioxidants and agricultural practice in Anopheles arabiensis sampled from an area of cotton fields in Northern Cameroon. Mol Ecol 2008, 17(4):1145-1155.

[69] Djouaka RF, Bakare AA, Coulibaly ON, Akogbeto MC, Ranson H, Hemingway J, Strode C: Expression of the cytochrome P450s, CYP6P3 and CYP6M2 are significantly elevated in multiple pyrethroid resistant populations of Anopheles gambiae s.s. from Southern Benin and Nigeria. BMC Genomics 2008, 9:538.

[70] Muller P, Donnelly MJ, Ranson H: Transcription profiling of a recently colonised pyrethroid resistant Anopheles gambiae strain from Ghana. BMC Genomics 2007, 8:36.

[71] Muller P, Warr E, Stevenson BJ, Pignatelli PM, Morgan JC, Steven A, Yawson AE, Mitchell SN, Ranson H, Hemingway J et al: Field-caught permethrin-resistant Anopheles gambiae overexpress CYP6P3, a P450 that metabolises pyrethroids. PLoS Genet 2008, 4(11):e1000286.

[72] Wondji CS, Irving H, Morgan J, Lobo NF, Collins FH, Hunt RH, Coetzee M, Hemingway J, Ranson H: Two duplicated P450 genes are associated with pyrethroid resistance in Anopheles funestus, a major malaria vector. Genome Res 2009, 19(3):452-459.

[73] Wondji CS, Morgan J, Coetzee M, Hunt RH, Steen K, Black WCt, Hemingway J, Ranson $\mathrm{H}$ : Mapping a quantitative trait locus (QTL) conferring pyrethroid resistance in the African malaria vector Anopheles funestus. BMC Genomics 2007, 8:34.

[74] Riveron JM, Irving H, Ndula M, Barnes KG, Ibrahim SS, Paine MJ, Wondji CS: Directionally selected cytochrome $\mathrm{P} 450$ alleles are driving the spread of pyrethroid resistance in the major malaria vector Anopheles funestus. Proc Natl Acad Sci U S A 2012, 110(1):252-257.

[75] Rongnoparut P, Boonsuepsakul S, Chareonviriyaphap T, Thanomsing N: Cloning of cytochrome P450, CYP6P5, and CYP6AA2 from Anopheles minimus resistant to deltamethrin. J Vector Ecol 2003, 28(2):150-158.

[76] Duangkaew P, Kaewpa D, Rongnoparut P: Protective efficacy of Anopheles minimus CYP6P7 and CYP6AA3 against cytotoxicity of pyrethroid insecticides in Spodoptera frugiperda (Sf9) insect cells. Trop Biomed 2011, 28(2):293-301. 
[77] Duangkaew P, Pethuan S, Kaewpa D, Boonsuepsakul S, Sarapusit S, Rongnoparut P: Characterization of mosquito CYP6P7 and CYP6AA3: differences in substrate preference and kinetic properties. Arch Insect Biochem Physiol 2011, 76(4):236-248.

[78] Ranson H, Cornel AJ, Fournier D, Vaughan A, Collins FH, Hemingway J: Cloning and Localization of a Glutathione S-transferase Class I Gene from Anopheles gambiae. J Biol Chem 1997, 272(9):5464-5967.

[79] Ranson H, Hemingway J: Mosquito glutathione transferases. Methods Enzymol 2005, 401:226-241.

[80] Fournier D, Bride JM, Poirie M, Berge JB, Plapp FW, Jr.: Insect glutathione S-transferases. Biochemical characteristics of the major forms from houseflies susceptible and resistant to insecticides. Journal of Biological Chemistry 1992, 267(3):1840-1845.

[81] Ranson H, Rossiter L, Ortelli F, Jensen B, Wang XL, Roth CW, Collins FH, Hemingway J: Identification of a novel class of insect glutathione S-transferases involved in resistance to DDT in the malaria vector Anopheles gambiae. Biochemical Journal 2001, 359 Part 2:295-304.

[82] Gunasekaran K, Muthukumaravel S, Sahu SS, Vijayakumar T, Jambulingam P: Glutathione $S$ transferase activity in Indian vectors of malaria: A defense mechanism against DDT. J Med Entomol 2011, 48(3):561-569.

[83] Prapanthadara LA, Ketterman AJ: Qualitative and quantitative changes in glutathione S-transferases in the mosquito Anopheles gambiae confer DDT-resistance. Biochem Soc Trans 1993, 21 ( Pt 3)(3):304S.

[84] Ranson H, Jensen B, Wang X, Prapanthadara L, Hemingway J, Collins FH: Genetic mapping of two loci affecting DDT resistance in the malaria vector Anopheles gambiae. Insect Mol Biol 2000, 9(5):499-507.

[85] Vontas JG, Small GJ, Hemingway J: Glutathione S-transferases as antioxidant defence agents confer pyrethroid resistance in Nilaparvata lugens. Biochem J 2001, 357(Pt 1): 65-72.

[86] Kostaropoulos I, Papadopoulos AI, Metaxakis A, Boukouvala E, PapadopoulouMourkidou E: Glutathione S-transferase in the defence against pyrethroids in insects. Insect Biochem Mol Biol 2001, 31(4-5):313-319.

[87] Fournier D: Mutations of acetylcholinesterase which confer insecticide resistance in insect populations. Chem Biol Interact 2005.

[88] Weill M, Lutfalla G, Mogensen K, Chandre F, Berthomieu A, Berticat C, Pasteur N, Philips A, Fort P, Raymond M: Comparative genomics: Insecticide resistance in mosquito vectors. Nature 2003, 423(6936):136-137. 
[89] Alout H, Labbe P, Berthomieu A, Pasteur N, Weill M: Multiple duplications of the rare ace-1 mutation F290V in Culex pipiens natural populations. Insect Biochem $\mathrm{Mol} \mathrm{Bi}$ ol 2009.

[90] Weill M, Malcolm C, Chandre F, Mogensen K, Berthomieu A, Marquine M, Raymond $\mathrm{M}$ : The unique mutation in ace- 1 giving high insecticide resistance is easily detectable in mosquito vectors. Insect Mol Biol 2004, 13(1):1-7.

[91] Djogbenou L, Chandre F, Berthomieu A, Dabire R, Koffi A, Alout H, Weill M: Evidence of introgression of the ace-1(R) mutation and of the ace-1 duplication in West African Anopheles gambiae s. s. PLoS ONE 2008, 3(5):e2172.

[92] Ffrench-Constant RH: The molecular and population genetics of cyclodiene insecticide resistance. Insect Biochem Mol Biol 1994, 24(4):335-345.

[93] Andreasen MH, Ffrench-Constant RH: In situ hybridization to the Rdl locus on polytene chromosome 3L of Anopheles stephensi. Med Vet Entomol 2002, 16(4):452-455.

[94] Du W, Awolola TS, Howell P, Koekemoer LL, Brooke BD, Benedict MQ, Coetzee M, Zheng L: Independent mutations in the Rdl locus confer dieldrin resistance to Anopheles gambiae and An. arabiensis. Insect Mol Biol 2005, 14(2):179-183.

[95] Davies TG, Field LM, Usherwood PN, Williamson MS: DDT, pyrethrins, pyrethroids and insect sodium channels. IUBMB Life 2007, 59(3):151-162.

[96] Donnelly MJ, Corbel V, Weetman D, Wilding CS, Williamson MS, Black WCt: Does $k d r$ genotype predict insecticide-resistance phenotype in mosquitoes? Trends Parasitol 2009, 25(5):213-219.

[97] Martinez Torres D, Chandre F, Williamson MS, Darriet F, Berge JB, Devonshire AL, Guillet P, Pasteur N, Pauron D: Molecular characterization of pyrethroid knockdown resistance $(k d r)$ in the major malaria vector Anopheles gambiae s.s. Insect Molecular Biology 1998, 7(2):179-184.

[98] Ranson H, Jensen B, Vulule JM, Wang X, Hemingway J, Collins FH: Identification of a point mutation in the voltage-gated sodium channel gene of Kenyan Anopheles gambiae associated with resistance to DDT and pyrethroids. Insect Molecular Biology 2000, 9(5):491-497.

[99] O'Reilly AO, Khambay BP, Williamson MS, Field LM, Wallace BA, Davies TG: Modelling insecticide-binding sites in the voltage-gated sodium channel. Biochem J 2006, 396(2):255-263.

[100] Jones CM, Liyanapathirana M, Agossa FR, Weetman D, Ranson H, Donnelly MJ, Wilding CS: Footprints of positive selection associated with a mutation (N1575Y) in the voltage-gated sodium channel of Anopheles gambiae. Proc Natl Acad Sci U S A 2012, 109(17):6614-6619. 
[101] Plapp FW, Jr.: The genetic basis of insecticide resistance in the house fly: evidence that a single locus plays a major role in metabolic resistance to insecticides. Pesticide Biochemistry and Physiology 1984, 22(2):194-201.

[102] Georghiou GP, Ariaratnam V, Pasternak ME, Lin CS: Organophosphorus multiresistance in Culex pipiens quinquefasciatus in California. Journal of Economic Entomology 1975, 68(4):461-467.

[103] Vontas J, David JP, Nikou D, Hemingway J, Christophides GK, Louis C, Ranson H: Transcriptional analysis of insecticide resistance in Anopheles stephensi using crossspecies microarray hybridization. Insect Mol Biol 2007, 16(3):315-324.

[104] Awolola TS, Oduola OA, Strode C, Koekemoer LL, Brooke B, Ranson H: Evidence of multiple pyrethroid resistance mechanisms in the malaria vector Anopheles gambiae sensu stricto from Nigeria. Trans R Soc Trop Med Hyg 2009, 103(11):1139-1145.

[105] Wood O, Hanrahan S, Coetzee M, Koekemoer L, Brooke B: Cuticle thickening associated with pyrethroid resistance in the major malaria vector Anopheles funestus. Parasit Vectors 2010, 3:67.

[106] Roberts DR, Chareonviriyaphap T, Harlan HH, Hshieh P: Methods of testing and analyzing excito-repellency responses of malaria vectors to insecticides. J Am Mosq Control Assoc 1997, 13(1):13-17.

[107] Chandre F, Darriet F, Duchon S, Finot L, Manguin S, Carnevale P, Guillet P: Modifications of pyrethroid effects associated with $k d r$ mutation in Anopheles gambiae. Medical and Veterinary Entomology 2000, 14(1):81-88.

[108] Gahan JB, Lindquist AW: DDT residual sprays applied in buildings to control Anopheles quadrimaculatus. Journal of Economic Entomology 1945, 38 (2):223-230.

[109] Chareonviriyaphap T, Roberts DR, Andre RG, Harlan HJ, Manguin S, Bangs MJ: Pesticide avoidance behavior in Anopheles albimanus, a malaria vector in the Americas. J Am Mosq Control Assoc 1997, 13(2):171-183.

[110] Garros C, Marchand RP, Quang NT, Hai NS, Manguin S: First record of Anopheles minimus $\mathrm{C}$ and significant decrease of An. minimus A in central Vietnam. J Am Mosq Control Assoc 2005, 21(2):139-143.

[111] Russell TL, Govella NJ, Azizi S, Drakeley CJ, Kachur SP, Killeen GF: Increased proportions of outdoor feeding among residual malaria vector populations following increased use of insecticide-treated nets in rural Tanzania. Malar J 2011, 10:80.

[112] Moiroux N, Gomez MB, Pennetier C, Elanga E, Djenontin A, Chandre F, Djegbe I, Guis H, Corbel V: Changes in Anopheles funestus Biting Behavior Following Universal Coverage of Long-Lasting Insecticidal Nets in Benin. J Infect Dis 2012, 206(10): 1622-1629. 
[113] WHO: Guidelines for testing mosquito adulticides intended for Indoor Residual Spraying (IRS) and Insecticide Treated Nets (ITNs). 2006, WHO/CDS/NTD/ WHOPES/GCDDP/2006.3.

[114] WHO: Report of the WHO Informal Consultation Tests procedures for insecticide resistance monitoring in malaria vectors, bio-efficacy and persistence of insecticides on treated surfaces. In. Geneva: World Health Organization: Parasitic Diseases and Vector Control (PVC)/Communicable Disease Control, Prevention and Eradication (CPE); 1998: 43.

[115] Williams J, Pinto J: Training Manual on Malaria Entomology; For Entomology and Vector Control Technicians (Basic Level) In. Edited by USAID. Washington, D.C.; 2012: 78.

[116] Ranson H, Abdallah H, Badolo A, Guelbeogo WM, Kerah-Hinzoumbe C, YangalbeKalnone E, Sagnon N, Simard F, Coetzee M: Insecticide resistance in Anopheles gambiae: data from the first year of a multi-country study highlight the extent of the problem. Malar J 2009, 8(1):299.

[117] Skovmand O, Bonnet J, Pigeon O, Corbel V: Median knock-down time as a new method for evaluating insecticide-treated textiles for mosquito control. Malar J 2008, $7: 114$.

[118] Brogdon WG, McAllister JC: Simplification of adult mosquito bioassays through use of time-mortality determinations in glass bottles. J Am Mosq Control Assoc 1998, 14(2): 159-164.

[119] World Health Organization: Techniques to detect insecticide resistance mechanisms (field and laboratory manual). In. Edited by WHO/CDS/CPC/MAL/98.6 WHO. Geneva: World Health Organization; 1998.

[120] Munhenga G, Masendu HT, Brooke BD, Hunt RH, Koekemoer LK: Pyrethroid resistance in the major malaria vector Anopheles arabiensis from Gwave, a malaria-endemic area in Zimbabwe. Malar J 2008, 7:247.

[121] Okoye PN, Brooke BD, Koekemoer LL, Hunt RH, Coetzee M: Characterisation of DDT, pyrethroid and carbamate resistance in Anopheles funestus from Obuasi, Ghana. Trans R Soc Trop Med Hyg 2008, 102(6):591-598.

[122] Kelly-Hope L, Ranson H, Hemingway J: Lessons from the past: managing insecticide resistance in malaria control and eradication programmes. Lancet Infect Dis 2008.

[123] Chouaibou M, Etang J, Brevault T, Nwane P, Hinzoumbe CK, Mimpfoundi R, Simard F: Dynamics of insecticide resistance in the malaria vector Anopheles gambiae s.l. from an area of extensive cotton cultivation in Northern Cameroon. Trop Med Int Health 2008, 13(4):476-486.

[124] Djegbe I, Boussari O, Sidick A, Martin T, Ranson H, Chandre F, Akogbeto M, Corbel $\mathrm{V}$ : Dynamics of insecticide resistance in malaria vectors in Benin: first evidence of the 
presence of L1014S kdr mutation in Anopheles gambiae from West Africa. Malaria Journal 2011, 10(1):261.

[125] Dabire KR, Diabate A, Pare-Toe L, Rouamba J, Ouari A, Fontenille D, Baldet T: Year to year and seasonal variations in vector bionomics and malaria transmission in a humid savannah village in west Burkina Faso. J Vector Ecol 2008, 33(1):70-75.

[126] Bass C, Nikou D, Donnelly MJ, Williamson MS, Ranson H, Ball A, Vontas J, Field LM: Detection of knockdown resistance $(k d r)$ mutations in Anopheles gambiae: a comparison of two new high-throughput assays with existing methods. Malar J 2007, 6:111.

[127] Corbel V, N'Guessan R, Brengues C, Chandre F, Djogbenou L, Martin T, Akogbeto M, Hougard JM, Rowland M: Multiple insecticide resistance mechanisms in Anopheles gambiae and Culex quinquefasciatus from Benin, West Africa. Acta Trop 2007, 101(3): 207-216.

[128] Diabate A: The Role of Agricultural Uses of Insecticides in Resistance to Pyrethroids in Anopheles gambiae S.L. in Burkina Faso. Am J Trop Med Hyg 2002, 67(6):617-622.

[129] Carnevale P, Toto JC, Guibert P, Keita M, Manguin S: Entomological survey and report of a knockdown resistance mutation in the malaria vector Anopheles gambiae from the Republic of Guinea. Trans R Soc Trop Med Hyg, 104(7):484-489.

[130] Yawson AE, McCall PJ, Wilson MD, Donnelly MJ: Species abundance and insecticide resistance of Anopheles gambiae in selected areas of Ghana and Burkina Faso. Med Vet Entomol 2004, 18(4):372-377.

[131] C. Fanello VP, A. della Torre, F. Santolamazza, G. Dolo, M. Coulibaly, A. Alloueche, C. F. Curtis, Y. T. Touré and M. Coluzzi: The pyrethroid knock-down resistance gene in the Anopheles gambiae complex in Mali and further indication of incipient speciation within An. gambiae s.s. Insect Molecular Biology 2003, 12(3):241-245.

[132] Czeher C, Labbo R, Arzika I, Duchemin J-B: Evidence of increasing Leu-Phe knockdown resistance mutation in Anopheles gambiae from Niger following a nationwide long-lasting insecticide-treated nets implementation. Malaria Journal 2008, 7(1):189.

[133] Awolola TS, Brooke BD, Hunt RH, Coetze M: Resistance of the malaria vector Anopheles gambiae s.s. to pyrethroid insecticides, in south-western Nigeria. Annals of Tropical Medicine and Parasitology 2002, 96(8):849-852.

[134] Koffi AA, Alou LP, Adja MA, Kone M, Chandre F, N'Guessan R: Update on resistance status of Anopheles gambiae s.s. to conventional insecticides at a previous WHOPES field site, "Yaokoffikro", 6 years after the political crisis in Cote d'Ivoire. Parasit Vectors 2012, 5:68.

[135] Dabire KR, Diabate A, Agostinho F, Alves F, Manga L, Faye O, Baldet T: Distribution of the members of Anopheles gambiae and pyrethroid knock-down resistance gene $(k d r)$ in Guinea-Bissau, West Africa. Bull Soc Pathol Exot 2008, 101(2):119-123. 
[136] Etang J, Fondjo E, Chandre F, Morlais I, Brengues C, Nwane P, Chouaibou M, Ndjemai H, Simard F: First report of knockdown mutations in the malaria vector Anopheles gambiae from Cameroon. Am J Trop Med Hyg 2006, 74(5):795-797.

[137] Ndjemai HN, Patchoke S, Atangana J, Etang J, Simard F, Bilong CF, Reimer L, Cornel A, Lanzaro GC, Fondjo E: The distribution of insecticide resistance in Anopheles gambiae s.l. populations from Cameroon: an update. Trans R Soc Trop Med Hyg 2009.

[138] Nwane P, Etang J, Chouaibou M, Toto JC, Kerah-Hinzoumbe C, Mimpfoundi R, Awono-Ambene HP, Simard F: Trends in DDT and pyrethroid resistance in Anopheles gambiae s.s. populations from urban and agro-industrial settings in southern Cameroon. BMC Infect Dis 2009, 9:163.

[139] Kerah-Hinzoumbe C, Peka M, Nwane P, Donan-Gouni I, Etang J, Same-Ekobo A, Simard F: Insecticide resistance in Anopheles gambiae from south-western Chad, Central Africa. Malar J 2008, 7:192.

[140] Janeira F, Vicente JL, Kanganje Y, Moreno M, Do Rosario VE, Cravo P, Pinto J: A primer-introduced restriction analysis-polymerase chain reaction method to detect knockdown resistance mutations in Anopheles gambiae. J Med Entomol 2008, 45(2): 237-241.

[141] Mourou JR, Coffinet T, Jarjaval F, Pradines B, Amalvict R, Rogier C, Kombila M, Pages F: Malaria transmission and insecticide resistance of Anopheles gambiae in Libreville and Port-Gentil, Gabon. Malar J 2010, 9:321.

[142] Himeidan YE, Chen H, Chandre F, Donnelly MJ, Yan G: Short report: permethrin and DDT resistance in the malaria vector Anopheles arabiensis from eastern Sudan. Am J Trop Med Hyg 2007, 77(6):1066-1068.

[143] Abdalla H, Matambo TS, Koekemoer LL, Mnzava AP, Hunt RH, Coetzee M: Insecticide susceptibility and vector status of natural populations of Anopheles arabiensis from Sudan. Transactions of the Royal Society of Tropical Medicine and Hygiene 2008, 102(3):263-271.

[144] Costantini C, Ayala D, Guelbeogo WM, Pombi M, Some CY, Bassole IH, Ose K, Fotsing JM, Sagnon N, Fontenille D et al: Living at the edge: biogeographic patterns of habitat segregation conform to speciation by niche expansion in Anopheles gambiae. BMC Ecol 2009, 9(1):16.

[145] Kulkarni MA, Malima R, Mosha FW, Msangi S, Mrema E, Kabula B, Lawrence B, Kinung'hi S, Swilla J, Kisinza W et al: Efficacy of pyrethroid-treated nets against malaria vectors and nuisance-biting mosquitoes in Tanzania in areas with long-term insecticide-treated net use. Trop Med Int Health 2007, 12(9):1061-1073.

[146] Kabula B, Tungu P, Matowo J, Kitau J, Mweya C, Emidi B, Masue D, Sindato C, Malima R, Minja J et al: Susceptibility status of malaria vectors to insecticides commonly used for malaria control in Tanzania. Trop Med Int Health 2012, 17(6):742-750. 
[147] Coleman M, Casimiro S, Hemingway J, Sharp B: Operational impact of DDT reintroduction for malaria control on Anopheles arabiensis in Mozambique. J Med Entomol 2008, 45(5):885-890.

[148] Ratovonjato J, Le Goff G, Rajaonarivelo E, Rakotondraibe EM, Robert V: [Recent observations on the sensitivity to pyrethroids and DDT of Anopheles arabiensis and Anopheles funestus in the central Highlands of Madagascar; preliminary results on the absence of the $k d r$ mutation in An. arabiensis]. Arch Inst Pasteur Madagascar 2003, 69(1-2):63-69.

[149] Ramphul U, Boase T, Bass C, Okedi LM, Donnelly MJ, Muller P: Insecticide resistance and its association with target-site mutations in natural populations of Anopheles gambiae from eastern Uganda. Trans R Soc Trop Med Hyg 2009.

[150] Verhaeghen K, Bortel WV, Roelants P, Okello PE, Talisuna A, Coosemans M: Spatiotemporal patterns in $k d r$ frequency in permethrin and DDT resistant Anopheles gambiae s.s. from Uganda. Am J Trop Med Hyg 2010, 82(4):566-573.

[151] Abate A, Hadis M: Susceptibility of Anopheles gambiae s.l. to DDT, malathion, permethrin and deltamethrin in Ethiopia. Trop Med Int Health 2011, 16(4):486-491.

[152] Ochomo E, Bayoh MN, Brogdon WG, Gimnig JE, Ouma C, Vulule JM, Walker ED: Pyrethroid resistance in Anopheles gambiae s.s. and Anopheles arabiensis in western Kenya: phenotypic, metabolic and target site characterizations of three populations. Med Vet Entomol 2012.

[153] Mathias DK, Ochomo E, Atieli F, Ombok M, Bayoh MN, Olang G, Muhia D, Kamau L, Vulule JM, Hamel MJ et al: Spatial and temporal variation in the $k d r$ allele L1014S in Anopheles gambiae s.s. and phenotypic variability in susceptibility to insecticides in Western Kenya. Malar J 2011, 10:10.

[154] Chanda E, Hemingway J, Kleinschmidt I, Rehman AM, Ramdeen V, Phiri FN, Coetzer S, Mthembu D, Shinondo CJ, Chizema-Kawesha E et al: Insecticide resistance and the future of malaria control in Zambia. PLoS ONE 2011, 6(9):e24336.

[155] Mouatcho JC, Munhenga G, Hargreaves K, Brooke BD, Coetzee M, Koekemoer LL: Pyrethroid resistance in a major African malaria vector Anopheles arabiensis from Mamfene, northern KwaZulu-Natal, South Africa. South African Journal of Science 2009, 105(3-4):127-131.

[156] Mouatcho JC, Hargreaves K, Koekemoer LL, Brooke BD, Oliver SV, Hunt RH, Coetzee M: Indoor collections of the Anopheles funestus group (Diptera: Culicidae) in sprayed houses in northern KwaZulu-Natal, South Africa. Malar J 2007, 6:30.

[157] Brooke BD, Kloke G, Hunt RH, Koekemoer LL, Temu EA, Taylor ME, Small G, Hemingway J, Coetzee M: Bioassay and biochemical analyses of insecticide resistance in southern African Anopheles funestus (Diptera: Culicidae). Bulletin of Entomological Research 2001, 91(4):265-272. 
[158] Cuamba N, Morgan JC, Irving H, Steven A, Wondji CS: High level of pyrethroid resistance in an Anopheles funestus population of the Chokwe District in Mozambique. PLoS ONE 2010, 5(6):e11010.

[159] Kloke RG, Nhamahanga E, Hunt RH, Coetzee M: Vectorial status and insecticide resistance of Anopheles funestus from a sugar estate in southern Mozambique. Parasit Vectors 2011, 4:16.

[160] Hunt R, Edwardes M, Coetzee M: Pyrethroid resistance in southern African Anopheles funestus extends to Likoma Island in Lake Malawi. Parasit Vectors 2010, 3:122.

[161] Wondji CS, Coleman M, Kleinschmidt I, Mzilahowa T, Irving H, Ndula M, Rehman A, Morgan J, Barnes KG, Hemingway J: Impact of pyrethroid resistance on operational malaria control in Malawi. Proc Natl Acad Sci U S A 2012, 109(47):19063-19070.

[162] Anto F, Asoala V, Anyorigiya T, Oduro A, Adjuik M, Owusu-Agyei S, Dery D, Bimi L, Hodgson A: Insecticide resistance profiles for malaria vectors in the Kassena-Nankana district of Ghana. Malaria Journal 2009, 8(1):81.

[163] Djouaka R, Irving H, Tukur Z, Wondji CS: Exploring mechanisms of multiple insecticide resistance in a population of the malaria vector Anopheles funestus in Benin. PLoS ONE 2011, 6(11):e27760.

[164] Dabire KR, Baldet T, Diabate A, Dia I, Costantini C, Cohuet A, Guiguemde TR, Fontenille D: Anopheles funestus (Diptera: Culicidae) in a humid savannah area of western Burkina Faso: bionomics, insecticide resistance status, and role in malaria transmission. J Med Entomol 2007, 44(6):990-997.

[165] Faraj C, Adlaoui E, Brengues C, Fontenille D, Lyagoubi M: [Resistance of Anopheles labranchiae to DDT in Morocco: identification of the mechanisms and choice of replacement insecticide]. Eastern Mediterranean health journal = La revue de sante de la Mediterranee orientale = al-Majallah al-sihhiyah li-sharq al-mutawassit 2008, 14(4):776-783.

[166] Mostafa AA, Allam KA: Studies on the present status of insecticides resistance on mosquitoes using the diagnostic dosages in El-Fayium Governorate, a spot area of malaria in Egypt. J Egypt Soc Parasitol 2001, 31(1):177-186.

[167] Balkew M, Elhassan I, Ibrahim M, GebreMichael T, Engers H: Very high DDT-resistant population of Anopheles pharoensis Theobald (Diptera: Culicidae) from Gorgora, northern Ethiopia. Parasite 2006, 13(4):327-239.

[168] Yadouleton AW, Padonou G, Asidi A, Moiroux N, Bio-Banganna S, Corbel V, N'Guessan R, Gbenou D, Yacoubou I, Gazard K et al: Insecticide resistance status in Anopheles gambiae in southern Benin. Malar J 2010, 9:83.

[169] Pinto J, Lynd A, Vicente JL, Santolamazza F, Randle NP, Gentile G, Moreno M, Simard F, Charlwood JD, do Rosario VE et al: Multiple Origins of Knockdown Resistance Mutations in the Afrotropical Mosquito Vector Anopheles gambiae. PLoS ONE 2007, 2(11):e1243. 
[170] della Torre A, Fanello C, Akogbeto M, Dossou-yovo J, Favia G, Petrarca V, Coluzzi M: Molecular evidence of incipient speciation within Anopheles gambiae s.s. in West Africa. Insect Mol Biol 2001, 10(1):9-18.

[171] Weill M, Chandre F, Brengues C, Manguin S, Akogbeto M, Pasteur N, Guillet P, Raymond M: The $k d r$ mutation occurs in the Mopti form of Anopheles gambiae s.s. through introgression. Insect Molecular Biology 2000, 9(5):451-455.

[172] Reimer LJ, Tripet F, Slotman M, Spielman A, Fondjo E, Lanzaro GC: An unusual distribution of the $k d r$ gene among populations of Anopheles gambiae on the island of Bioko, Equatorial Guinea. Insect Mol Biol 2005, 14(6):683-688.

[173] Protopopoff N, Verhaeghen K, Van Bortel W, Roelants P, Marcotty T, Baza D, D'Alessandro U, Coosemans M: A significant increase in $k d r$ in Anopheles gambiae is associated with an intensive vector control intervention in Burundi highlands. Trop Med Int Health 2008, 13(12):1479-1487.

[174] Pinto J, Lynd A, Elissa N, Donnelly MJ, Costa C, Gentile G, Caccone A, do Rosario VE: Co-occurrence of East and West African $k d r$ mutations suggests high levels of resistance to pyrethroid insecticides in Anopheles gambiae from Libreville, Gabon. Med Vet Entomol 2006, 20(1):27-32.

[175] Moreno M, Vicente JL, Cano J, Berzosa PJ, de Lucio A, Nzambo S, Bobuakasi L, Buatiche JN, Ondo M, Micha F et al: Knockdown resistance mutations $(k d r)$ and insecticide susceptibility to DDT and pyrethroids in Anopheles gambiae from Equatorial Guinea. Trop Med Int Health 2008, 13(3):430-433.

[176] Verhaeghen K, Van Bortel W, Roelants P, Backeljau T, Coosemans M: Detection of the East and West African $k d r$ mutation in Anopheles gambiae and Anopheles arabiensis from Uganda using a new assay based on FRET/Melt Curve analysis. Malaria Journal 2006, 5(1):16.

[177] Koekemoer LL, Spillings BL, Christian RN, Lo TC, Kaiser ML, Norton RA, Oliver SV, Choi KS, Brooke BD, Hunt RH et al: Multiple insecticide resistance in Anopheles gambiae (Diptera: Culicidae) from Pointe Noire, Republic of the Congo. Vector Borne Zoonotic Dis 2011, 11(8):1193-1200.

[178] Reimer L, Fondjo E, Patchoke S, Diallo B, Lee Y, Ng A, Ndjemai HM, Atangana J, Traore SF, Lanzaro G et al: Relationship between $k d r$ mutation and resistance to pyrethroid and DDT insecticides in natural populations of Anopheles gambiae. J Med Entomol 2008, 45(2):260-266.

[179] Badolo A, Traore A, Jones CM, Sanou A, Flood L, Guelbeogo WM, Ranson H, Sagnon $\mathrm{N}$ : Three years of insecticide resistance monitoring in Anopheles gambiae in Burkina Faso: resistance on the rise? Malar J 2012, 11:232.

[180] Santolamazza F, Calzetta M, Etang J, Barrese E, Dia I, Caccone A, Donnelly MJ, Petrarca $\mathrm{V}$, Simard F, Pinto J et al: Distribution of knock-down resistance mutations in 
Anopheles gambiae molecular forms in west and west-central Africa. Malar J 2008, 7(1): 74.

[181] Ridl F, Bass C, Torrez M, Govender D, Ramdeen V, Yellot L, Edu A, Schwabe C, Mohloai P, Maharaj R et al: A pre-intervention study of malaria vector abundance in Rio Muni, Equatorial Guinea: Their role in malaria transmission and the incidence of insecticide resistance alleles. Malaria Journal 2008, 7(1):194

[182] Reimer L, Fondjo E, Patchok, Salomon, Diallo B, Lee Y, Ng A, Ndjemai HM, Atangana J, Traore SF et al: Relationship Between $k d r$ Mutation and Resistance to Pyrethroid and DDT Insecticides in Natural Populations of Anopheles gambiae. Journal of Medical Entomology 2008, 45:260-266.

[183] Matambo TS, Abdalla H, Brooke BD, Koekemoer LL, Mnzava A, Hunt RH, Coetzee M: Insecticide resistance in the malarial mosquito Anopheles arabiensis and association with the $k d r$ mutation. Medical and Veterinary Entomology 2007, 21(1):97-102.

[184] Kulkarni M, Rowland M, Alifrangis M, Mosha F, Matowo J, Malima R, Peter J, Kweka E, Lyimo I, Magesa S et al: Occurrence of the leucine-to-phenylalanine knockdown resistance $(k d r)$ mutation in Anopheles arabiensis populations in Tanzania, detected by a simplified high-throughput SSOP-ELISA method. Malaria Journal 2006, 5(1):56.

[185] Chen H, Githeko AK, Githure JI, Mutunga J, Zhou G, Yan G: Monooxygenase Levels and Knockdown Resistance $(k d r)$ Allele Frequencies in Anopheles gambiae and Anopheles arabiensis in Kenya. Journal of Medical Entomology 2008, 45:242-250.

[186] Etang J, Manga L, Toto JC, Guillet P, Fondjo E, Chandre F: Spectrum of metabolicbased resistance to DDT and pyrethroids in Anopheles gambiae s.l. populations from Cameroon. J Vector Ecol 2007, 32(1):123-133.

[187] Hargreaves K, Hunt RH, Brooke BD, Mthembu J, Weeto MM, Awolola TS, Coetzee M: Anopheles arabiensis and An. quadriannulatus resistance to DDT in South Africa. Med Vet Entomol 2003, 17(4):417-422.

[188] Amenya DA, Naguran R, Lo TC, Ranson H, Spillings BL, Wood OR, Brooke BD, Coetzee M, Koekemoer LL: Over expression of a cytochrome P450 (CYP6P9) in a major African malaria vector, Anopheles funestus, resistant to pyrethroids. Insect Mol Biol 2008, 17(1):19-25.

[189] Somboon P, Prapanthadara LA, Suwonkerd W: Insecticide susceptibility tests of Anopheles minimus s.l., Aedes aegypti, Aedes albopictus, and Culex quinquefasciatus in northern Thailand. Southeast Asian J Trop Med Public Health 2003, 34(1):87-93.

[190] Verhaeghen K, Van Bortel W, Trung HD, Sochantha T, Coosemans M: Absence of knockdown resistance suggests metabolic resistance in the main malaria vectors of the Mekong region. Malar J 2009, 8:84. 
[191] Chareonviriyaphap T, Rongnoparut P, Chantarumporn P, Bangs MJ: Biochemical detection of pyrethroid resistance mechanisms in Anopheles minimus in Thailand. J Vector Ecol 2003, 28(1):108-116.

[192] Rodpradit P, Boonsuepsakul S, Chareonviriyaphap T, Bangs MJ, Rongnoparut P: Cytochrome P450 genes: molecular cloning and overexpression in a pyrethroid-resistant strain of Anopheles minimus mosquito. J Am Mosq Control Assoc 2005, 21(1):71-79.

[193] Verhaeghen K, Van Bortel W, Trung HD, Sochantha T, Keokenchanh K, Coosemans M: Knockdown resistance in Anopheles vagus, An. sinensis, An. paraliae and An. peditaeniatus populations of the Mekong region. Parasit Vectors 2011, 3(1):59.

[194] Kang S, Jung J, Lee S, Hwang H, Kim W: The polymorphism and the geographical distribution of the knockdown resistance $(k d r)$ of Anopheles sinensis in the Republic of Korea. Malar J 2012, 11:151.

[195] Tan WL, Wang ZM, Li CX, Chu HL, Xu Y, Dong YD, Wang ZC, Chen DY, Liu H, Liu $\mathrm{DP}$ et al: First report on co-occurrence knockdown resistance mutations and susceptibility to beta-cypermethrin in Anopheles sinensis from Jiangsu Province, China. PLoS ONE 2012, 7(1):e29242.

[196] Syafruddin D, Hidayati AP, Asih PB, Hawley WA, Sukowati S, Lobo NF: Detection of $1014 \mathrm{~F} k d r$ mutation in four major Anopheline malaria vectors in Indonesia. Malar J 2010, 9:315.

[197] Singh OP, Dykes CL, Das MK, Pradhan S, Bhatt RM, Agrawal OP, Adak T: Presence of two alternative $k d r$-like mutations, L1014F and L1014S, and a novel mutation, V1010L, in the voltage gated Na+ channel of Anopheles culicifacies from Orissa, India. Malar J 2010, 9:146.

[198] Mishra AK, Chand SK, Barik TK, Dua VK, Raghavendra K: Insecticide resistance status in Anopheles culicifacies in Madhya Pradesh, central India. J Vector Borne Dis 2012, 49(1):39-41.

[199] Sharma SN, Shukla RP, Raghavendra K: Susceptibility status of An. fluviatilis and An. culicifacies to DDT, deltamethrin and lambdacyhalothrin in District Nainital, Uttar Pradesh. Indian J Malariol 1999, 36(3-4):90-93.

[200] Singh OP, Dykes CL, Lather M, Agrawal OP, Adak T: Knockdown resistance $(k d r)$ like mutations in the voltage-gated sodium channel of a malaria vector Anopheles stephensi and PCR assays for their detection. Malar J 2011, 10:59.

[201] Tikar SN, Mendki MJ, Sharma AK, Sukumaran D, Veer V, Prakash S, Parashar BD: Resistance status of the malaria vector mosquitoes, Anopheles stephensi and Anopheles subpictus towards adulticides and larvicides in arid and semi-arid areas of India. J Insect Sci 2011, 11:85. 
[202] Baruah K, Lal S: A report on the susceptibility status of Anopheles minimus (Theobald) against DDT and deltamethrin in three districts of Assam. J Vector Borne Dis 2004, 41(1-2):42-44.

[203] Karunaratne SH, Hemingway J: Malathion resistance and prevalence of the malathion carboxylesterase mechanism in populations of mosquito vectors of disease in Sri Lanka. Bull World Health Organ 2001, 79(11):1060-1064.

[204] Kelly-Hope LA, Yapabandara AM, Wickramasinghe MB, Perera MD, Karunaratne SH, Fernando WP, Abeyasinghe RR, Siyambalagoda RR, Herath PR, Galappaththy GN et al: Spatiotemporal distribution of insecticide resistance in Anopheles culicifacies and Anopheles subpictus in Sri Lanka. Trans R Soc Trop Med Hyg 2005, 99(10):751-761.

[205] Perera MD, Hemingway J, Karunaratne SP: Multiple insecticide resistance mechanisms involving metabolic changes and insensitive target sites selected in anopheline vectors of malaria in Sri Lanka. Malar J 2008, 7:168.

[206] Surendran SN, Jude PJ, Weerarathne TC, Parakrama Karunaratne SH, Ramasamy R: Variations in susceptibility to common insecticides and resistance mechanisms among morphologically identified sibling species of the malaria vector Anopheles subpictus in Sri Lanka. Parasit Vectors 2012, 5:34.

[207] Mittal PK, Wijeyaratne P, Pandey S: Status of Insecticide Resistance of Malaria, Kalaazar and Japanese Encephalitis Vectors in Bangladesh, Bhutan, India and Nepal (BBIN). In. Edited by Project EH. Washington 2004.

[208] Rowland M: Location of the gene for malathion resistance in Anopheles stephensi (Diptera: Culicidae) from Pakistan. J Med Entomol 1985, 22(4):373-380.

[209] Abai MR, Mehravaran A, Vatandoost H, Oshaghi MA, Javadian E, Mashayekhi M, Mosleminia A, Piyazak N, Edallat H, Mohtarami F et al: Comparative performance of imagicides on Anopheles stephensi, main malaria vector in a malarious area, southern Iran. J Vector Borne Dis 2008, 45(4):307-312.

[210] Lak SH, vatandoost H, Entezarmahdi MR, Ashraf H, Abai MR, Nazari M: Monitoring of Insecticide Resistance in Anopheles sacharovi (Favre, 1903) in Borderline of Iran, Armenia, Naxcivan and Turkey, 2001. Iranian J Publ Health 2002, 31(3-4):96-99.

[211] Vatandoost H, Mashayekhi M, Abaie MR, Aflatoonian MR, Hanafi-Bojd AA, Sharifi I: Monitoring of insecticides resistance in main malaria vectors in a malarious area of Kahnooj district, Kerman province, southeastern Iran. J Vector Borne Dis 2005, 42(3): 100-108.

[212] Malcolm CA: Current status of pyrethroid resistance in anophelines. Parasitol Today 1988, 4(7):S13-15.

[213] Quinones ML, Suarez MF: Irritability to DDT of natural populations of the primary malaria vectors in Colombia. J Am Mosq Control Assoc 1989, 5(1):56-59. 
[214] Suarez MF, Quinones ML, Palacios JD, Carrillo A: First record of DDT resistance in Anopheles darlingi. J Am Mosq Control Assoc 1990, 6(1):72-74.

[215] Fonseca-Gonzalez I: Estatus de la resistencia a insecticidas de los vectores primarios de malaria y dengue en Antioquia, Chocó, Norte de Santander y Putumayo, Colombia. Universidad de Antioquia, Colombia; 2008.

[216] Fonseca-Gonzalez I, Cardenas R, Quinones ML, McAllister J, Brogdon WG: Pyrethroid and organophosphates resistance in Anopheles (N.) nuneztovari Gabaldon populations from malaria endemic areas in Colombia. Parasitol Res 2009, 105(5):1399-1409.

[217] Chareonviriyaphap T, Golenda CF, Roberts DR, Andre RG: Identification of Elevated Esterase Activity in a Pyrethroid-Resistant Population of Anopheles albimanus Wiedemann. ScienceAsia 1999, 25 153-156.

[218] Brogdon WG, McAllister JC, Corwin AM, Cordon Rosales C: Independent selection of multiple mechanisms for pyrethroid resistance in Guatemalan Anopheles albimanus (Diptera: Culicidae). Journal of Economic Entomology 1999, 92(2):298-302.

[219] Zamora Perea E, Balta Leon R, Palomino Salcedo M, Brogdon WG, Devine GJ: Adaptation and evaluation of the bottle assay for monitoring insecticide resistance in disease vector mosquitoes in the Peruvian Amazon. Malar J 2009, 8:208.

[220] Hemingway J, Penilla RP, Rodriguez AD, James BM, Edge W, Rogers H, Rodriguez $\mathrm{MH}$ : Resistance management strategies in malaria vector mosquito control. A largescale field trial in Southern Mexico. Pesticide Science 1997, 51(3):375-382.

[221] Dzul FA, Patricia Penilla R, Rodriguez AD: [Susceptibility and insecticide resistance mechanisms in Anopheles albimanus from the southern Yucatan Peninsula, Mexico]. Salud Publica Mex 2007, 49(4):302-311.

[222] South Africa Department of Health: Malaria Updates. In. Pretoria, S.A: S.A.D.H.; 2003.

[223] Maharaj R, Mthembu DJ, Sharp BL: Impact of DDT re-introduction on malaria transmission in KwaZulu-Natal. S Afr Med J 2005, 95(11):871-874.

[224] Roberts DR, Manguin S, Mouchet J: DDT house spraying and re-emerging malaria. Lancet 2000, 356(9226):330-332.

[225] Protopopoff N, Van Bortel W, Marcotty T, Van Herp M, Maes P, Baza D, D'Alessandro U, Coosemans M: Spatial targeted vector control in the highlands of Burundi and its impact on malaria transmission. Malar J 2007, 6:158.

[226] Trape J-F, Tall A, Diagne N, Ndiath O, Ly AB, Faye J, Dieye-Ba F, Roucher C, Bouganali $\mathrm{C}$, Badiane A et al: Malaria morbidity and pyrethroid resistance after the introduction of insecticide-treated bednets and artemisinin-based combination therapies: a longitudinal study. The Lancet Infectious Diseases 2011. 
[227] Lengeler C: Insecticide-treated bed nets and curtains for preventing malaria. Cochrane Database of Systematic reviews 2009(2):1-58.

[228] Kitau J, Oxborough RM, Tungu PK, Matowo J, Malima RC, Magesa SM, Bruce J, Mosha FW, Rowland MW: Species shifts in the Anopheles gambiae complex: do LLINs successfully control Anopheles arabiensis? PLoS ONE 2012, 7(3):e31481.

[229] Bradley J, Matias A, Schwabe C, Vargas D, Monti F, Nseng G, Kleinschmidt I: Increased risks of malaria due to limited residual life of insecticide and outdoor biting versus protection by combined use of nets and indoor residual spraying on Bioko Island, Equatorial Guinea. Malar J 2012, 11:242.

[230] Henry MC, Assi SB, Rogier C, Dossou-Yovo J, Chandre F, Guillet P, Carnevale P: Protective efficacy of lambda-cyhalothrin treated nets in Anopheles gambiae pyrethroid resistance areas of Cote d'Ivoire. Am J Trop Med Hyg 2005, 73(5):859-864.

[231] Corbel V, Akogbeto M, Damien GB, Djenontin A, Chandre F, Rogier C, Moiroux N, Chabi J, Banganna B, Padonou GG et al: Combination of malaria vector control interventions in pyrethroid resistance area in Benin: a cluster randomised controlled trial. Lancet Infect Dis 2012, 12(8):617-626.

[232] Darriet F, N' Guessan R, Koffi AA, Konan L, Doannio JMC, Chandre F, Carnevale P: Impact of the resistance to pyrethroids on the efficacy of impregnated bednets used as a means of prevention against malaria: results of the evaluation carried out with deltamethrin SC in experimental huts. Bulletin de la Société de Pathologie Exotique 2000, 93(2):131-134.

[233] Corbel V, Chandre F, Brengues C, Akogbeto M, Lardeux F, Hougard JM, Guillet P: Dosage-dependent effects of permethrin-treated nets on the behaviour of Anopheles gambiae and the selection of pyrethroid resistance. Malar J 2004, 3(1):22.

[234] N'Guessan R, Corbel V, Akogbeto M, Rowland M: Reduced efficacy of insecticidetreated nets and indoor residual spraying for malaria control in pyrethroid resistance area, Benin. Emerg Infect Dis 2007, 13(2):199-206.

[235] N'Guessan R, Asidi A, Boko P, Odjo A, Akogbeto M, Pigeon O, Rowland M: An experimental hut evaluation of PermaNet(R) 3.0, a deltamethrin-piperonyl butoxide combination net, against pyrethroid-resistant Anopheles gambiae and Culex quinquefasciatus mosquitoes in southern Benin. Trans R Soc Trop Med Hyg 2010, 104(12):758-765.

[236] Asidi A, N'Guessan R, Akogbeto M, Curtis C, Rowland M: Loss of household protection from use of insecticide-treated nets against pyrethroid-resistant mosquitoes, Benin. Emerg Infect Dis 2012, 18(7):1101-1106.

[237] Osse R, Gnanguenon V, Sezonlin M, Aikpon R, Padonou G, Yadouleton A, Akogbeto M: Relationship between the presence of $k d r$ and Ace-1 mutations and the infection with Plasmodium falciparum in Anopheles gambiae s.s. in Benin. Journal of Parassitology $\mathcal{E}$ Vector Biology 2012, 4(3):31-39. 
[238] Moiroux N, Boussari O, Djenontin A, Damien G, Cottrell G, Henry MC, Guis H, Corbel V: Dry season determinants of malaria disease and net use in Benin, West Africa. PLoS ONE 2012, 7(1):e30558.

[239] Poupardin R, Reynaud S, Strode C, Ranson H, Vontas J, David JP: Cross-induction of detoxification genes by environmental xenobiotics and insecticides in the mosquito Aedes aegypti: impact on larval tolerance to chemical insecticides. Insect Biochem Mol Biol 2008, 38(5):540-551.

[240] IRAC: Prevention and Management of Insecticide Resistance in Vectors of Public Health Importance In: Resistance Management for Sustainable Agriculture and Improved Public Health : Second Edition 2010 Insecticide Resistance Action Commitee; 2010: 72pp.

[241] Georghiou GP, Taylor CE: Genetic and biological influences in the evolution of insecticide resistance. Journal of Economic Entomology 1977, 70(3):319-323.

[242] Denholm I, Rowland MW: Tactics for managing pesticide resistance in arthropods: theory and practice. Annu Rev Entomol 1992, 37:91-112.

[243] Djogbenou L, Weill M, Hougard JM, Raymond M, Akogbeto M, Chandre F: Characterization of insensitive acetylcholinesterase (ace-1R) in Anopheles gambiae (Diptera: Culicidae): resistance levels and dominance. J Med Entomol 2007, 44(5):805-810.

[244] Berticat C, Bonnet J, Duchon S, Agnew P, Weill M, Corbel V: Costs and benefits of multiple resistance to insecticides for Culex quinquefasciatus mosquitoes. BMC Evol Biol 2008, 8:104.

[245] Moore JH, Williams SM: Traversing the conceptual divide between biological and statistical epistasis: systems biology and a more modern synthesis. Bioessays 2005, 27(6):637-646.

[246] Shono T, Zhang L, Scott JG: Indoxacarb resistance in the house fly, Musca domestica. Pesticide Biochemistry and Physiology 2004, 80(2):106-112.

[247] Shono T, Kasai S, Kamiya E, Kono Y, Scott JG: Genetics and mechanisms of permethrin resistance in the YPER strain of house fly. Pesticide Biochemistry and Physiology 2002, 73(1):27-36.

[248] Scott JG, Shono T, Georghiou GP: Genetic analysis of permethrin resistance in the house fly, Musca domestica L. Experientia 1984, 40(12):1416-1418.

[249] Hardstone MC, Leichter CA, Scott JG: Multiplicative interaction between the two major mechanisms of permethrin resistance, $k d r$ and cytochrome P450-monooxygenase detoxification, in mosquitoes. J Evol Biol 2009, 22(2):416-423.

[250] Berticat C, Boquien G, Raymond M, Chevillon C: Insecticide resistance genes induce a mating competition cost in Culex pipiens mosquitoes. Genet Res 2002, 79(1):41-47. 
[251] Agnew P, Berticat C, Bedhomme S, Sidobre C, Michalakis Y: Parasitism increases and decreases the costs of insecticide resistance in mosquitoes. Evolution Int J Org Evolution 2004, 58(3):579-586.

[252] Foster SP, Harrington R, Devonshire AL, Denholm I, Devine GJ, Kenward MG: Comparative survival of insecticide-susceptible and resistant peach-potato aphids, Myzus persicae (Sulzer) (Hemiptera: Aphididae), in low temperature field trials. Bull Ent Res 1996, 86:17-27.

[253] Shi MA, Lougarre A, Alies C, Fremaux I, Tang ZH, Stojan J, Fournier D: Acetylcholinesterase alterations reveal the fitness cost of mutations conferring insecticide resistance. BMC Evol Biol 2004, 4:5.

[254] Djogbenou L, Noel V, Agnew P: Costs of insensitive acetylcholinesterase insecticide resistance for the malaria vector Anopheles gambiae homozygous for the G119S mutation. Malar J 2010, 9(1):12.

[255] Brogdon WG, McAllister JC: Insecticide resistance and vector control. Emerg Infect Dis 1998, 4(4):605-613.

[256] Diabate A, Baldet T, Chandre F, Akoobeto M, Guiguemde TR, Darriet F, Brengues C, Guillet P, Hemingway J, Small GJ et al: The role of agricultural use of insecticides in resistance to pyrethroids in Anopheles gambiae s.l. in Burkina Faso. Am J Trop Med Hyg 2002, 67(6):617-622.

[257] Yadouleton A, Martin T, Padonou G, Chandre F, Asidi A, Djogbenou L, Dabire R, Aikpon R, Boko M, Glitho I et al: Cotton pest management practices and the selection of pyrethroid resistance in Anopheles gambiae population in northern Benin. Parasit Vectors 2011, 4:60.

[258] Harrison G: Mosquitoes, malaria and man: A history of hostilities since 1880.; 1978.

[259] Read AF, Lynch PA, Thomas MB: How to make evolution-proof insecticides for malaria control. PLoS Biol 2009, 7(4):e1000058.

[260] Roush RT, Hoy CW, Ferro DN, Tingey WM: Insecticide resistance in the Colorado potato beetle (Coleoptera: Chrysomelidae): influence of crop rotation and insecticide use. Journal of Economic Entomology 1990, 83(2):315-319.

[261] Georghiou GP: Insecticide resistance and prospects for its management. Residue Reviews 1980, 76:131-145.

[262] Tabashnik BE: Managing resistance with multiple pesticide tactics: theory, evidence, and recommendations. J Econ Entomol 1989, 82(5):1263-1269.

[263] Chitnis N, Schapira A, Smith T, Steketee R: Comparing the effectiveness of malaria vector-control interventions through a mathematical model. Am J Trop Med Hyg 2010, 83(2):230-240. 
[264] Yakob L, Dunning R, Yan G: Indoor residual spray and insecticide-treated bednets for malaria control: theoretical synergisms and antagonisms. J R Soc Interface 2011, 8(59):799-806.

[265] World Health Organization: Global strategic framework for integrated vector management. Geneva; 2004.

[266] Curtis CF: Theoretical models of the use of insecticide mixtures for management of resistance. Bull Ent Res 1985, 75: 259-265.

[267] Hougard JM, Poudiougo P, Guillet P, Back C, Akpoboua LK, Quillevere D: Criteria for the selection of larvicides by the Onchocerciasis Control Programme in west Africa. Ann Trop Med Parasitol 1993, 87(5):435-442.

[268] WHO: Pesticides and their application for the control of vectors and pests of public health importance; Sixth edition. In. Edited by WHO/CDS/NTD/WHOPES/GCDPP/ 2006.1 WHO, Geneva; 2006: 1-125.

[269] Corbel V, Chabi J, Dabire RK, Etang J, Nwane P, Pigeon O, Akogbeto M, Hougard JM: Field efficacy of a new mosaic long-lasting mosquito net (PermaNet 3.0) against pyrethroid-resistant malaria vectors: a multi centre study in Western and Central Africa. Malar J 2010, 9:113.

[270] Killeen GF, Okumu FO, N'Guessan R, Coosemans M, Adeogun A, Awolola S, Etang J, Dabire RK, Corbel V: The importance of considering community-level effects when selecting insecticidal malaria vector products. Parasit Vectors 2011, 4:160.

[271] Mani GS: Evolution of resistance in the presence of two insecticides. Genetics 1985, 109(4):761-783.

[272] Roush RT: Designing resistance management programs: how can you choose? Pesticide Science 1989, 26(4):423-441.

[273] Hougard JM, Corbel V, N'Guessan R, Darriet F, Chandre F, Akogbeto M, Baldet T, Guillet P, Carnevale P, Traore-Lamizana M: Efficacy of mosquito nets treated with insecticide mixtures or mosaics against insecticide resistant Anopheles gambiae and Culex quinquefasciatus (Diptera: Culicidae) in Cote d'Ivoire. Bull Entomol Res 2003, 93(6):491-498.

[274] Asidi AN, N'Guessan R, Koffi AA, Curtis CF, Hougard JM, Chandre F, Corbel V, Darriet F, Zaim M, Rowland MW: Experimental hut evaluation of bednets treated with an organophosphate (chlorpyrifos-methyl) or a pyrethroid (lambdacyhalothrin) alone and in combination against insecticide-resistant Anopheles gambiae and Culex quinquefasciatus mosquitoes. Malar J 2005, 4(1):25.

[275] Ohashi K, Nakada K, Ishiwatari T, Miyaguchi J, Shono Y, Lucas JR, Mito N: Efficacy of pyriproxyfen-treated nets in sterilizing and shortening the longevity of Anopheles gambiae (Diptera: Culicidae). J Med Entomol 2012, 49(5):1052-1058. 
[276] Mosqueira B, Duchon S, Chandre F, Hougard JM, Carnevale P, Mas-Coma S: Efficacy of an insecticide paint against insecticide-susceptible and resistant mosquitoes - part 1: laboratory evaluation. Malar J 2010, 9:340.

[277] Ngufor C, N'Guessan R, Boko P, Odjo A, Vigninou E, Asidi A, Akogbeto M, Rowland $\mathrm{M}$ : Combining indoor residual spraying with chlorfenapyr and long-lasting insecticidal bed nets for improved control of pyrethroid-resistant Anopheles gambiae: an experimental hut trial in Benin. Malar J 2011, 10:343.

[278] Kleinschmidt I, Schwabe C, Shiva M, Segura JL, Sima V, Mabunda SJ, Coleman M: Combining indoor residual spraying and insecticide-treated net interventions. Am J Trop Med Hyg 2009, 81(3):519-524.

[279] Okumu FO, Moore SJ: Combining indoor residual spraying and insecticide-treated nets for malaria control in Africa: a review of possible outcomes and an outline of suggestions for the future. Malar J 2011, 10:208.

[280] Brosseau L, Drame PM, Besnard P, Toto JC, Foumane V, Le Mire J, Mouchet F, Remoue F, Allan R, Fortes F et al: Human antibody response to Anopheles saliva for comparing the efficacy of three malaria vector control methods in Balombo, Angola. PLoS ONE 2012, 7(9):e44189.

[281] Bill_\&_Melinda_Gates_Fondation, Boston_Consulting_Group: Market Assessment for Public Health Pesticide Products. In.; 2007. 
